\title{
ARTÍCULOS
}

\section{COMO EL ÁNIMA AL CUERPO. LOS PILOTOS REALES DE LA ARMADA DE MAGALLANES (1519-1522).}

\author{
Carmen Mena García \\ Universidad de Sevilla \\ cmena@us.es
}

\begin{abstract}
Resumen: Los pilotos fueron pieza fundamental para el éxito de la gran aventura ultramarina encabezada por España y Portugal desde fines del siglo XV. En esta ocasión, nos ocupamos de los avezados tripulantes que participaron en la primera expedición a las Molucas (1519-1522) encomendada al portugués Hernando de Magallanes. Seis hombres gobernaban los cinco barcos de la armada de la Especiería -tres portugueses y otros tres castellanos- y todos tenían la consideración de pilotos de Sus Altezas, es decir, estaban permanentemente al servicio de la Corona y cobraban un salario mensual de la Casa de la Contratación. Sobre fuentes documentales, crónicas de la época y una bibliografía especializada ofrecemos en estas páginas una aproximación a sus recorridos biográficos.
\end{abstract}

Palabras clave: Pilotos reales, Armada de la Especiería, Molucas, Magallanes, Esteban Gómez, Andrés de San Martín, Juan Carvallo, Juan Rodríguez Serrano, Vasco Gallego, Juan Rodríguez Mafra.

Tittle: LIKE THE SOUL TO THE HUMAN BODY. THE ROYAL PILOTS OF THE MAGALLANES NAVY (1519-1522).

Abstract: Pilots were a key factor in the success of the great maritime adventure lead by Spain and Portugal since the $15^{\text {th }}$ century. This article focuses in one specific episode: the first expedition to the Molucca Islands (1519-1522) commended to the Portuguese Ferdinand Magellan. Six men -three Portuguese and three from Castille- manned the five ships of the Armada de la Especiería. All of them were officially declared Pilots of their Royal Highnesses. As civil servants of the crown they perceived a monthly salary from the Casa de Contratación. On documentary sources, chronicles of the time and a specialized bibliography we offer in these pages an approach to his biographical journeys.

Keywords: Royal Pilots, Armada de la Especiería, Molucca Islands, Magellan, Andrés de San Martín, Juan Carvallo, Juan Rodríguez Serrano, Vasco Gallego, Juan Rodríguez Mafra.

\section{Introducción}

Decía un experimentado marino que "el piloto en la nao es así como el ánima al cuerpo humano" y no le faltaba razón ${ }^{1}$. El piloto era el responsable técnico del barco,

${ }^{1}$ CHAVES, Alonso de. Espejo de Navegantes, ca. 1537. Edición y estudio preliminar de Paulino

Recibido: 03-01-2021

Aceptado: 01-06-2021

Cómo citar este artículo: MENA GARCíA, Carmen. Como el ánima al cuerpo humano. Los pilotos reales de la Armada de Magallanes (1519-1522). Naveg@mérica. Revista electrónica editada por la Asociación Española de Americanistas [en línea]. 2021, n. 27. Disponible en: $<$ http://revistas.um.es/navegamerica $>$. [Consulta: Fecha de consulta]. ISSN 1989-211X. 
el encargado de gobernarlo, siguiendo el derrotero preciso con ayuda de los instrumentos náuticos y de su bagaje en el oficio, hasta que por fin la nave llegaba a su destino. El alma, el espíritu que daba vida a aquellos cascarones de nueces, robustos y ennegrecidos. Nada más y nada menos. En la época de las exploraciones oceánicas cuando España se lanzaba al mundo en busca de nuevas tierras y nuevos mares los pilotos de aquellas embarcaciones fueron una pieza fundamental del engranaje. Pero los buenos pilotos siempre escasearon. Para la flota de cinco barcos encomendada a Fernando de Magallanes en su viaje a las Molucas fueron seleccionados hasta seis pilotos reales, lo que equivale a decir que más de la mitad de la plantilla al servicio de la Contratación en 1519, los más expertos marinos de aquellos momentos, participaron en aquella aventura, tan grandiosa por el objetivo alcanzado -la primera circunnavegación del globo- como desgraciada por la pérdida de vidas humanas.

Aunque con frecuencia embarcaban un par de pilotos en cada nao, para que uno (piloto de respeto) pudiera sustituir al otro en caso de necesidad, sólo la nao San Antonio iba gobernada por dos tripulantes: Juan Rodríguez Mafra y Andrés de San Martín, aunque éste último debió de ser reclutado más por sus conocimientos en astronomía y cosmografía que por su experiencia como marino. Como piloto mayor de la flota fue designado el portugués Esteban Gómez, lo que demuestra la confianza que el monarca depositaba en él, seguramente por su experiencia en otros viajes de los portugueses a la India.

Algunos, como Juan Rodríguez Serrano, ya eran viejos, otros, como Vasco Gallego y Juan Rodríguez Mafra, analfabetos ${ }^{2}$, lo que indica que tenían una gran experiencia marinera pero muy escasos conocimientos teóricos. La ciencia náutica apenas se había desarrollado y los instrumentos de medida eran todavía muy imprecisos. Por eso no debe extrañar que a comienzos del siglo XVI se valorase la experiencia por encima de la ciencia y que marinos que no sabían leer, ni siquiera estampar su firma, llegasen a pilotar los barcos. Se guiaban sencillamente por su inteligencia natural, por su destreza en el oficio y por sus muchos años de práctica en la navegación ${ }^{3}$. Los grandes pilotos de la era de los Descubrimientos fueron auténticos lobos de mar.

\section{Esteban Gómez. Un piloto en Nueva York}

El portugués Estevão Gomes, natural de Oporto ${ }^{4}$, había entrado al servicio de la corona castellana el 10 de febrero de 1518, luego era uno de los fichajes más

\footnotetext{
Castañeda, Mariano Cuesta y Pilar Hernández. Madrid: Museo Naval, 1983, p. 162.

${ }^{2}$ Así se desprende de las huellas testimoniales conservadas en los protocolos notariales de Sevilla. Ya lo observó GIL FERNÁNDEZ, Juan. El libro de Marco Polo anotado por Cristóbal Colón. Madrid: Alianza, 1987, p. XXXVII.

${ }^{3}$ PÉREZ MALLAINA, Pablo E. Los hombres del Océano. Vida cotidiana de los tripulantes de las flotas de Indias, siglo XVI. Sevilla: Diputación Provincial de Sevilla, 1992, p. 91. MENA GARCIA, Carmen. Sevilla y las flotas de Indias. La gran armada de Castilla del Oro, 1513-1514. Sevilla: Fundación EI Monte; Universidad de Sevilla, 1999 (2商ed.), p. 183.

${ }^{4}$ El cronista Joao Barros se refiere al piloto como "Gómez de Oporto". MEDINA, José Toribio. El portugués Esteban Gómez al servicio de España: Estudio histórico. Santiago de Chile: Imprenta Elzeviriana, 1908, p. 9.
} 
recientes de la Casa de la Contratación ${ }^{5}$. No se sabe en qué momento abandonó Portugal a la búsqueda de nuevos horizontes, aunque el cronista João de Barros aseguraba que vino a España con Magallanes, lo cual podría ser cierto, dado que ambos eran paisanos y conocidos. En ese caso, su llegada a Sevilla debió producirse el 20 de octubre de $1517^{6}$. No obstante, la cuestión no resulta nada clara pues Pigafetta sostenía en su crónica que el piloto Gómez había llegado a la corte castellana antes de que lo hiciera Magallanes. ¿A quién creer de los dos? Que guardaba una relación estrecha con su compatriota y con el grupo de nobles portugueses instalados en Sevilla lo demuestra un hecho bien significativo: antes de embarcarse para el gran viaje, Esteban Gómez confió una parte de su hacienda a Diego Barbosa, el alcaide de los Reales Alcázares, y a su esposa, es decir, a los suegros de Magallanes ${ }^{7}$. ¿Por qué se quebró entonces la amistad entre ambos portugueses?

Cumplidos ya los 33 años cuando llega a España ${ }^{8}$, sea en compañía de Magallanes o no, el piloto Gómez, un marino experimentado, que ya había participado en algunos viajes castellanos y portugueses ${ }^{9}$, tenía sus propios planes. Él también deseaba comandar una expedición en busca del estrecho imaginado, a lo largo y ancho de esa barrera de tierra que era el Nuevo Mundo. Pero el monarca antepuso el proyecto magallánico, tal vez porque confiaba más en él, y después de prometer a Esteban Gómez que le daría una nueva oportunidad en una empresa propia, lo obligó a participar en la expedición a las Molucas, viajando en la Trinidad como piloto mayor de la flota ${ }^{10}$ y responsable de los aspectos náuticos, aunque subordinado a Magallanes en todo lo demás. Dado que estaba al servicio de la Corona, Gómez no podía negarse a acatar las órdenes reales, pero es de suponer que aquella decisión lo irritaría profundamente, indisponiéndolo con su compatriota, ya antes de abandonar Sevilla. El mismo Pigafetta lo recogió en su diario: "Este piloto era Esteban Gómez que odiaba a Magallanes por la única razón de que cuando éste vino a España para proponer al emperador el ir a las islas Molucas por el oeste, Gómez había pedido y estaba a punto de conseguir para una expedición el mando de unas carabelas" ${ }^{\prime 1}$. Pero existe otra teoría sobre el motivo que desencadenó el enfado del piloto con su capitán general, según la cual a Esteban Gómez no debió sentarle nada bien la reestructuración en el mando realizada por Magallanes tras el motín de San Julián, relegándolo de la Trinidad a la San Antonio,

\footnotetext{
${ }^{5}$ Archivo General de Indias (en adelante AGI), Indiferente 419, L.7, F.693V. Real Cédula a los oficiales de la Casa de la Contratación. Valladolid, 10, febrero, 1518. ¿Lo recomendó Magallanes? Es probable. Pero obsérvese que su nombramiento como piloto al servicio de la Corona española se produjo un mes antes de que Magallanes fuese recibido como capitán de la armada de la Especiería (22, marzo, 1518).

${ }^{6}$ Citado por MEDINA, José Toribio. El portugués Esteban Gómez... Op. cit., p. 9.

${ }^{7}$ AGI, Indiferente, 429, L.9, F.105R. Justicia a Esteban Gómez en el pleito con Diego Barbosa. Valladolid, 20, abril, 1523.

${ }^{8}$ En 1530 Esteban Gómez declaró tener cuarenta y seis años, poco más o menos, de lo que se deduce que había nacido allá por 1484. MEDINA, José Toribio. El portugués Esteban Gómez... Op. cit., p. 8.

${ }^{9}$ Así lo declaró él mismo: "que algunas veces ha ido en algunas armadas, así de Castilla como de Portugal". Ibídem.

${ }_{10}^{10}$ Su nombramiento se produjo el 19 de abril de 1519.

${ }^{11}$ PIGAFETTA, Antonio. Primer Viaje en torno al globo. Madrid: Espasa Calpe, 1999, p. 65.
} 
en lugar de confiarle una capitanía, que era lo que éste deseaba ${ }^{12}$.

Sea como fuera, la ruptura se produjo muy pronto. En el mes de octubre de 1520, mientras la flota buscaba desesperadamente la salida del estrecho, Esteban Gómez, que probablemente gobernaba la nao San Antonio desde la tragedia de San Julián, hostigó a los compañeros de su barco convenciéndoles de la necesidad de regresar a España. Cuando Álvaro de la Mezquita, el pariente de Magallanes, y entonces capitán de la nao, se percató de ello, reaccionó con furia contra el piloto. Salieron a relucir las espadas y en una rápida maniobra Mezquita resultó herido en la mano izquierda y Gómez en el muslo. La tripulación consiguió reducir al capitán Álvaro de la Mezquita, tomándolo preso, y el barco dio la vuelta a España comandado por Esteban Gómez y Jerónimo Guerra, éste convertido ahora de escribano en tesorero y capitán de la San Antonio ${ }^{13}$.

Durante algún tiempo Magallanes dio orden de buscar el barco perdido en los intricados callejones del estrecho. Dejó señales a cada paso. No sabía cómo interpretar lo sucedido. Pero poco a poco se impuso la idea de que la San Antonio había abandonado la escuadra para regresar en busca del capitán Juan de Cartagena y del capellán quienes un tiempo atrás habían sido abandonados a su suerte en la tierras de la Patagonia. Es sabido que los marinos eran gente muy supersticiosa que atribuían explicaciones mágicas a cualquier suceso inexplicable. Y no dudaban en recurrir a influencias extravagantes, como la conjunción de los astros o el movimiento de las estrellas. Una misteriosa predicción realizada por un astrólogo en medio del océano ya avisaba del desastre. En efecto, si vale el testimonio del grumete Martín de Ayamonte, en aquel momento de general desconcierto: "la presunción en todos fue que el piloto Esteban Gómez, portugués, prendería al dicho capitán y tornaba en busca de Juan de Cartagena y del clérigo, y que esta presunción fue por una conclusión que un astrólogo ahí sacó por mandado del dicho Fernando de Magallanes" ${ }^{14}$. ¿Se refería al cosmógrafo y astrónomo Andrés de San Martín? ¿A quién si no?

Después de un largo y duro viaje, en el que los 63 tripulantes ${ }^{15}$ de la San Antonio sufrieron lo indecible por falta de alimentos, la solitaria nao llegó al puerto sevillano

\footnotetext{
${ }^{12}$ MEDINA, José Toribio. El portugués Esteban Gómez... Op. cit., p. 19. Durante la conjura contra Magallanes en San Julián, el piloto portugués formó parte de los amotinados, pero por razones que se desconocen no fue castigado.

${ }^{13} \mathrm{AGI}$, Patronato, 34, R.6. Relación del sueldo debido a los 107 tripulantes de la expedición a las islas Molucas capitaneada por Magallanes. [Jerónimo Guerra] "que fue por escribano de la nao Sant Antonio y vino en ella por tesorero, venció de sueldo de escribano del 10 de agosto de 1519, que partió de Sevilla hasta 2 de abril de 1520, que falleció Luis de Mendoça (Mendoza), en cuyo lugar entró..."

${ }^{14}$ Relación de Martín de Ayamonte, en MAZÓN, Tomás. Elcano. Viaje a la Historia. Madrid: Ediciones Encuentros, 2020, p. 283.

${ }^{15}$ AGI, Patronato, 34, R.14. Carta de los oficiales de la Casa de la Contratación de las Indias al emperador Carlos V, sobre regreso de la nao "San Antonio" y denuncias de sus mandos de los excesos de Fernando de Magallanes. Sevilla, mayo, 1521. López de Recalde informó que en la San Antonio habían llegado Jerónimo Guerra y el piloto Esteban Portugués, "y con ellos hasta sesenta hombres entre marineros y sobresalientes". Si añadimos a Mezquita, el total sumaba los 63 tripulantes.
} 
de las Muelas el 6 de mayo de $1521^{16}$, provocando un enorme revuelo, especialmente entre las autoridades de la Contratación, que no supieron cómo interpretar aquel hecho. Inmediatamente se abrió una pesquisa para averiguar lo sucedido y mientras tanto Esteban Gómez, Jerónimo Guerra, Juan Chinchilla, Francisco Angulo y Pedro Asturiano fueron hechos prisioneros, primero en Sevilla y luego, en Burgos, mientras que al resto de la marinería y a los sobresalientes, para ahorrar los gastos de su manutención, se les permitió deambular libremente por las calles de Sevilla, pero no se les pagó su sueldo a la espera de que el monarca resolviera ${ }^{17}$. Cuando pocos días más tarde el obispo Fonseca, que se encontraba en Burgos, tuvo conocimiento de estos sucesos montó en cólera y ordenó a los oficiales de la Contratación que enviaran a los presos a su presencia de inmediato. Dispuso también que del oro que acababa de llegar de Puerto Rico se aprestase una carabela para ir a la Patagonia al rescate de Juan de Cartagena y su compañero de destierro ${ }^{18}$.

El piloto Esteban Gómez no fue sancionado por haber desertado con la nao San Antonio ni por haber tomado preso al capitán Mezquita ${ }^{19}$. Por el contrario, el monarca le confió en 1523 la dirección de una nueva expedición ${ }^{20}$ para "yr a descubrir el Catayo Oriental, del que tenéis noticia y relación por donde hacéis fundamento descubrir hasta las nuestras islas de Maluco", que tenía por objeto la búsqueda del paso a la Especiería, esta vez por el norte ${ }^{21}$ :

"Iba este piloto (Esteban Gómez) en demanda de un estrecho que se ofreció de hallar en tierra de Bacallaos, por donde pudiese ir a la Especiería en más breve que por otra ninguna parte, y traer clavos y canela y las otras especias y medicinas que de allá se traen... Y como Cristóbal Colón, Fernando Cortés, Gil González de Ávila y otros no lo habían hallado del golfo de Urabá hasta la Florida, acordó él subir más arriba"22.

\footnotetext{
${ }^{16}$ A su regreso a Sevilla, Esteban Gómez se atribuyó el descubrimiento de las islas Malvinas aunque el dato no está suficientemente probado.

${ }_{17}$ AGI, Indiferente, 420, L.8, F.294R-295R. Carta del obispo de Burgos, Juan Rodríguez de Fonseca, a los oficiales de la Casa de la Contratación de Sevilla, sobre las medidas a tomar a raíz de la llegada a Sevilla de la nao San Antonio, perteneciente a la Armada enviada para descubrir la Especiería. Burgos, 29, mayo, 1521. AGI, Patronato, 34, R.17.Carta de los oficiales de la Casa de la Contratación de las Indias al emperador Carlos V, sobre regreso de la nao "San Antonio" y denuncias de sus mandos de los excesos de Fernando de Magallanes. Sevilla, mayo, 1521. AGI, Patronato, 34, R.14. Traslado de la información presentada por poderes por Álvaro de la Mezquita, acerca de la toma de la nao "San Antonio" por Gaspar de Quesada y Juan de Cartagena, el 1ํ de abril de 1520.

${ }_{18} \mathrm{AGI}$, Indiferente, 420, L.8. Carta de Juan Rodríguez de Fonseca a los oficiales de la Contratación de Sevilla. Burgos, 29, mayo, 1521.

${ }^{19}$ AGI, Contratación, 5675B, L.2. Desconozco qué tipo de relación mantenía Esteban Gómez con el lobby burgalés, pero lo cierto es que en diciembre de 1522 cobraba en la Contratación el sueldo del piloto ausente Diego Díaz, "mercader burgalés" (factor de Cristóbal de Haro), como apoderado del citado piloto. No fue la primera ni la única vez.

${ }^{20}$ AGI, Contratación, 5675B, L.2. Desconozco qué tipo de relación mantenía Esteban Gómez con el lobby burgalés, pero lo cierto es que en diciembre de 1522 cobraba en la Contratación el sueldo del piloto ausente Diego Díaz, "mercader burgalés" (factor de Cristóbal de Haro), como apoderado del citado piloto. No fue la primera ni la única vez.

${ }^{21}$ AGI, Indiferente, 420, L.9. Capitulación con Esteban Gómez, piloto de S.A., para el descubrimiento del Catayo oriental hasta las Molucas. Valladolid, 27, marzo, 1523. AGI, Indiferente, 415, L.1. Asiento con Esteban Gómez. Valladolid, 27, marzo, 1523.

${ }^{22}$ LÓPEZ DE GÓMARA, Francisco. Historia General de las Indias. Caracas: Biblioteca Ayacucho,
} 
Tal y como se sinceraba Pedro Mártir de Anglería en su carta al arzobispo de Cosenza, reinaba en aquellos momentos más el entusiasmo que la confianza. Pero, en cualquier caso, valía la pena intentarlo.

[a Esteban Gómez] se le está preparando una sola nave carabela pues no llevará más orden que ver si en las varias revueltas y vastos rodeos de este nuestro Océano, se encuentra salida para ir al que comúnmente llaman el Gran Can. Hay tal furor en buscar ese estrecho, que se exponen a mil peligros, pues cualquiera que lo encontrara, si se puede encontrar, obtendrá en sumo grado la gracia del César y gran autoridad. Porque si se hallara paso del Océano Austral al Septentrional sería más fácil el viaje a las islas que crían los aromas y las perlas. Y no valdría la empeñada cuestión con el Rey de Portugal... Pero hay poca esperanza del estrecho.

Difícil evitar comparaciones. Aunque siguiendo otro derrotero, se trataba de la misma misión encargada a Magallanes unos años atrás, sólo que ahora los medios y recursos empleados eran modestísimos: una sola nao y una pequeña tripulación de veintiocho hombres, que zarpó de la Coruña el 24 de septiembre de $1524^{23}$. Fue la primera empresa organizada por la recién fundada Casa de la Especiería bajo la dirección del burgalés Cristóbal de Haro. La aventura fracasó por razones fáciles de imaginar, pero sirvió para explorar un inmenso espacio de la costa atlántica de los actuales Estados Unidos y del Canadá, más allá de los $42^{\circ}$ de latitud norte, recogidos en un mapa -Esteban Gómez era cartógrafo como San Martín- que amplió el conocimiento de la geografía de la época. Fue la primera expedición que exploró las costas de Nueva York y Boston. Allí quedó reflejada aquella gran aventura con topónimos tales como Bahía de San Antonio (actual Bahía de Hudson), mientras que todo el litoral visitado fue conocido como Tierra de Esteban Gómez²

El piloto portugués continuó por muchos años al servicio de la Corona española. En 1533 presentó un curioso proyecto de construcción de ciertas instalaciones en la ribera del Guadalquivir para reparar y poner en monte los navíos, evitando así que las naves fueran remolcadas hasta tres leguas de distancia para las citadas tareas, que contó con el beneplácito del Consejo de Indias. El cabildo sevillano también dio el visto bueno al proyecto, comprometiéndose a financiarlo, pero dos años más tarde aún seguía sin ejecutarse ${ }^{25}$.

La labor de Esteban Gómez se vio recompensada en 1534 con la concesión de un escudo de armas, señoreado por una preciosa carabela, como no podía ser menos $^{26}$. El último destino del que se tiene noticia lo sitúa en la actual Argentina, tres

\footnotetext{
1978, p. 178.

${ }^{23}$ AGI, Indiferente, 420, L.9. Capitulación de descubrimiento con Esteban Gómez. Valladolid, 27, marzo, 1523.

${ }^{24}$ Véase el mapa de la "Tierra que descubrió el piloto Estevan Gómez" recogido en el Islario General de todas las islas del mundo de Alonso de Santa Cruz. Sobre este viaje, véase VIGNERAS, Louis André. El viaje de Esteban Gómez a Norteamérica. Revista de Indias. 1957, n. 68, pp. 189-207.

${ }^{25}$ AGI, Indiferente, 1961, L.3. Carta acordada del Consejo de Indias a los oficiales de la Casa de la Contratación. Madrid, 1, julio, 1533. AGI, Indiferente, 1961, L.3. Real Cédula al concejo de Sevilla para que en el plazo de tiempo que se señala comiencen a construir un edificio en la ribera del Guadalquivir para calafatear y reparar las naos. Madrid, 16, junio, 1535.

${ }^{26} \mathrm{AGI}$, Indiferente, 422, L.16. Real Provisión concediendo escudo de armas a Esteban Gómez, piloto
} 
años después. El 15 de enero de 1537 Pedro de Mendoza, gobernador del Río de la Plata, despachó desde Buenos Aires una expedición de rescate en busca del capitán Juan de Ayolas, en la que viajaba el piloto Esteban Gómez. A partir de aquí se pierde la pista de este marino infatigable. Se desconoce si pereció en Buenos Aires, en las aguas del Paraná o en las selvas del Paraguay ${ }^{27}$.

\section{Andrés de San Martín, el astrólogo}

Cuando Andrés de San Martín recibió la orden de embarcar en la flota de la Especiería seguro que respiró aliviado ${ }^{28}$. No atravesaba por su mejor momento: arrastraba una importante deuda con la tesorería y tenía el sueldo de piloto embargado. Para evitar su huida a otro país, se le había prohibido salir del Reino y navegar el océano, mientras no cancelase el descubierto. San Martín probablemente pensó que con su ajustado salario nunca podría librarse de esa pesada losa que cargaba sobre sus espaldas. Ahora se presentaba ante él una oportunidad de oro para volver a la mar y sobre todo para sanear su economía. Sí, la ocasión era excelente. ¿Pero de qué deuda se trataba?

Durante el tiempo en el que estuvo encargado de custodiar los fondos del oro, perlas y palo de Brasil de la real hacienda, como ayudante del tesorero Matienzo, a cuyas órdenes trabajó durante algunos años, el piloto sevillano había cometido un desfalco de 300 ducados de oro (112.500 maravedís). Sin duda, una importante suma y una deshonra para su persona. Por ahora había conseguido devolver hasta 100 ducados $^{29}$, dado que los oficiales de la Contratación le retenían periódicamente una parte del salario, pero todavía la cantidad que restaba por satisfacer (200 ducados) seguía siendo elevada. En esta agobiante situación se hallaba San Martín cuando un buen día el rey Carlos decidió aprobar el proyecto de Magallanes y Faleiro. Se requerían tripulantes para los barcos, marinos con experiencia y mucho mejor si poseían conocimientos astronómicos. Ni los unos ni los otros sobraban. Alguien puso sobre la mesa el nombre de San Martín y el soberano dio su visto bueno, ordenándole que se incorporase de inmediato a la flota, pese a que tenía prohibido tripular cualquier barco.

La armada de la Especiería, la nueva empresa de la Corona, se presentaba a los ojos de San Martín como una tabla de salvación, como una gran oportunidad que no podía desaprovechar. La Corona necesitaba pilotos y San Martín ansiaba liberarse de su deuda, de manera que nada más recibir su nombramiento, en la primavera de 1519 , se atrevió a solicitar al rey que con ocasión del proyectado viaje le condonase los 200 ducados que aún debía:

"Et por vuestra parte me ha seydo suplicado et pedido por merçed que porque vos estáys nonbrado para yr a nos seruyr en este viaje de que van por capitanes Fernando de Magallanes e Ruy Falero al descubrimiento de la Espeçería, vos

\footnotetext{
mayor que sirvió en las armadas de Hernando Magallanes, del comendador Loaysa y la de la Florida hasta la isla de los Bacalaos en busca de un paso para la isla de la Especiería. Toledo, 21, mayo, 1534.

${ }_{27}$ MEDINA, José Toribio. El portugués Esteban Gómez... Op. cit., p. 126.

${ }^{28}$ Andrés de San Martín fue designado para viajar en la flota por Real Cédula de 8 de mayo de 1519.

${ }^{29}$ Se especifica que equivalentes a 37.500 maravedís "desta moneda que se agora usa".
} 
fiziese merçed de los dichos dozientos ducados que asy nos soys obligado a pagar o como la mi merçed fuese".

La respuesta no se hizo esperar. En Barcelona, el 8 de mayo de 1519, el monarca en un gesto de generosidad, o tal vez apremiado por los acontecimientos, respondió a San Martín que lo liberaba de la mitad del débito, al tiempo que le anunciaba haber dado órdenes a Matienzo, el tesorero de la Contratación:

"que no vos ponga enpedimiento en vuestra yda, e que ponga por pagados en su quenta los dichos çien ducados (de los 200 pendientes) de que yo asý vos fago merçed, que por la presente mando que le sean reçibidos e pasados en quenta al dicho nuestro thesorero" ${ }^{\prime 30}$.

Pero ¿qué hoja de servicios exhibía San Martín en estos momentos? ¿Por qué resultaba tan imprescindible para aquella empresa?

Tal vez la participación del piloto sevillano en la expedición que dio la vuelta al mundo sea una de las etapas más conocidas de toda su trayectoria. Indudablemente la relevancia de esta gran hazaña y las numerosas fuentes que se han conservado justifican la fijeza de los historiadores por este momento histórico y el descuido a la hora de indagar en su recorrido anterior. Pero, por fortuna, hoy día se disponen de nuevos datos sobre la vida familiar y la trayectoria profesional de San Martín que nos acercan al personaje y nos permiten conocerlo mejor ${ }^{31}$. Se sabe que sus padres eran Juan de Logroño y María Hernández, vecinos de Sevilla, y que Andrés tenía al menos un hermano, llamado Cristóbal de San Martín. De sus relaciones con una humilde mujer de escasos recursos nacieron sus dos hijas: Juana y María de San Martín que crecieron bajo el cuidado de los abuelos paternos.

Respecto a su hoja de servicios, los primeros indicios sobre el piloto datan de 1508 y lo relacionan más con cuestiones terrenales que marítimas. Para entonces San Martín había entrado al servicio de Francisco de Pinelo, un agente de la banca genovesa y uno de los más ricos mercaderes de Sevilla en donde desempeñaba, merced a sus cuantiosas rentas, el cargo de jurado y fiel ejecutor ${ }^{32}$. Amigo personal de Colón y protegido de los reyes, Pinelo había sido designado factor de la nueva Casa de la Contratación instalada en Sevilla en 1503. Desde ese preciso momento, la Casa se convirtió en el faro que guiaba las nuevas expediciones oceánicas y dirigía todo el trasiego de barcos, hombres y mercancías. En este ambiente debía moverse San Martín hasta que un buen día conoció al genovés y entró a su servicio como empleado de su banco. Muy satisfecho y confiado debía de estar Pinelo de su

\footnotetext{
${ }^{30}$ Archivo Histórico Provincial de Sevilla (en adelante AHPS), 2229P, fols. 2181r-2182v. Andrés de San Martín, cosmógrafo y piloto real, reconoce una deuda con la reina Juana y su hijo Carlos I, así como con el doctor Sancho Ortiz de Matienzo, tesorero de la Contratación. Sevilla, 18, Julio, 1519.

${ }^{31}$ Para más información véase MENA GARCIA, Carmen. Conocer y dominar los astros. El piloto Andrés de San Martín y la expedición de Magallanes/Del Cano. Temas Americanistas. Jun. 2020, n. 44, pp. 197-231.

${ }^{32}$ Archivo General de Simancas (en adelante AGS), RGS, 148809, 19. Merced de una fiel ejecutoria de la ciudad de Sevilla, a Francisco Pinelo, vecino de la misma, por vacación del licenciado del Alcázar. Valladolid, 11, septiembre, 1488. Durante un tiempo se encargó también del despacho del correo para los reyes. Cfr. AGS, Cámara de Castilla, CED, 1, 4, 1. Despacho a Francisco Pinelo, fiel ejecutor de Sevilla. Medina del Campo, 19, marzo, 1494.
} 
criado cuando, pocos días antes de morir, decidió nombrarlo procurador en todos sus asuntos $^{33}$. La otra persona elegida para una misión tan delicada se llamaba Américo Vespucio.

Las idas y venidas de San Martín, cumpliendo los encargos del banquero-factor le permitiría conocer bien de cerca los entresijos de la Contratación y entablar amistad con los otros colegas del triunvirato, como el doctor Sancho Ortiz de Matienzo, compañero de Pinelo al frente de la tesorería de la Contratación, o el contador Juan López de Recalde. En efecto, resulta razonable pensar que durante esta etapa Andrés de San Martín debió de cumplir fielmente sus tareas, pues al poco de la muerte de Pinelo, acaecida en marzo de $1509^{34}$, lo encontramos de nuevo implicado en actividades de la Casa, esta vez como criado y hombre de confianza de Sancho Ortiz de Matienzo, tesorero, además de jurista y canónigo de la catedral de Sevilla $^{35}$. Fruto de esta relación se conservan algunas pistas muy valiosas. Sabemos, por ejemplo, que unos años más tarde, Matienzo reconocía en una notaría sevillana a Andrés de San Martín como "su criado" al tiempo que declaraba que éste había sido "su oficial y factor en el oficio de tesorero en la Casa de la Contratación", desde el 1 de abril de 1511 hasta fines de agosto de 1515, con la importante misión de recibir y cobrar todo el oro, las perlas y el palo de Brasil que, procedentes de las Indias, correspondían a la Corona ${ }^{36}$. Un encargo de gran responsabilidad que no fue capaz de desempeñar dignamente, como luego pudo demostrarse.

Todo apunta a que San Martín fue un alumno aventajado de Américo Vespucio, el gran explorador y cosmógrafo florentino que dio nombre a todo un continente, siendo elegido en 1508, y en virtud de sus muchas cualidades, como el primer Piloto Mayor de la Contratación. Con él probablemente aprendió San Martín a confeccionar preciosos mapas y cartas de marear, así como los primeros rudimentos sobre cosmografía y astronomía. Todos consideraban a Vespucio como un gran maestro, tanto que Pedro Mártir de Anglería y hasta el mismo Fonseca, "el patrono de los navegantes", alabaron sus dotes cartográficas poco después de su muerte: "Tuvimos en las manos (...) muchos pergaminos que los marinos llaman cartas de marear, una de las cuales la habían dibujado los portugueses, en la cual dicen que puso mano Américo Vespucio, florentino, hombre perito en este arte" ${ }^{37}$. A través de Américo, San Martín debió de conocer a su sobrino, el joven Juan Vespucio quien, según cuenta Anglería, había heredado de su tío, además de los instrumentos náuticos, sus libros

\footnotetext{
${ }^{33}$ Oficio XV, Libro II. Escribanía de Bernal González Vallesillo. 27, abril, 1508. CAPS, tomo X. Sevilla, 1997.

${ }^{34}$ Pinelo falleció en Sevilla el 21 de marzo de 1509 y fue reemplazado como factor de la Casa de la Contratación por el Vasco Ochoa de Isasaga el 2 de abril de ese mismo año. SCHÄFER, Ernesto. El Consejo Real y Supremo de las Indias. Su historia, organización y labor administrativa hasta la terminación de la Casa de Austria. Sevilla: Imprenta M. Carmona, 1935. 2 vol, p. 14, nota 5.

${ }^{35}$ El doctor Sancho Ortiz de Matienzo era abad de Jamaica, aunque nunca pisó las Indias, protonotario apostólico, canónigo de la Santa Iglesia Catedral de Sevilla y tesorero de la Casa de la Contratación.

${ }^{36}$ Oficio IV, Libro III. Escribanía de Manuel Sigura, 18, julio, 1519, seguida de otra escritura de la misma fecha y contenido similar. CAPS, tomo VII, Sevilla, 1990.

37 ANGLERÍA, Pedro Mártir de. Décadas del Nuevo Mundo. Edición de Ramón Alba. Madrid: Ediciones Polifemo, 1989, p. 157.
} 
y tablas astronómicas, "la pericia del arte de navegar y de calcular los grados"38.

En 1512, unos meses después del fallecimiento de Américo Vespucio, la confección y custodia del Padrón Real fue encargada a Juan Díaz de Solís, el nuevo piloto mayor de la Casa y a Juan Vespucio, el sobrino de Américo. Sólo éste estaba facultado para sacar copias en pergamino y a un precio razonable del citado Padrón Real y entregarlas a los pilotos que lo solicitaran. Ahora bien, se concedió un permiso especial para que también Andrés de San Martín pudiera realizar estas copias $^{39}$. Siendo una misión tan delicada, ¿por qué se otorgaba a nuestro piloto y "no a otra persona" semejante privilegio? La respuesta salta a la vista: San Martín era ya por entonces un reputado cartógrafo que gozaba de la consideración y reconocimiento de los oficiales de la Contratación y, por ende, del monarca.

Dos años más tarde encontramos de nuevo a Vespucio y a San Martín compartiendo un mismo proyecto y sobre un mismo escenario. Se trata de la gran armada de Castilla del Oro dirigida por Pedrarias Dávila en $1514^{40}$. Vespucio, viaja a bordo de Nuestra Señora de la Concepción, una carabela que había sido comprada en Portugal por Vicente Yáñez Pinzón como capitana de la citada flota ${ }^{41}$. Mientras que Andrés de San Martín tripulaba, tal vez, la San Antón. Cuando se incorpora a la flota de Pedrarias, el piloto sevillano, además de en asuntos relacionados con la tesorería de la Contratación, ya lleva trabajando dos años al servicio de la Corona. En Burgos, el 22 de mayo de 1512 había sido nombrado piloto de Su Alteza con 20.000 maravedís de salario, por cierto uno de los más bajos de toda la plantilla. Se desconoce si había participado en algún viaje anterior a las Indias o seguía enfrascado en las labores cartográficas.

No obstante, hay indicios suficientes para conocer los sueños y ambiciones que pueblan su cabeza. Desde el fallecimiento de su maestro Américo Vespucio, se considera con capacidad y méritos suficientes como para heredar su puesto de Piloto Mayor, pero las circunstancias no le favorecen. Él mismo reconocía años después en una carta dirigida al monarca que había perdido aquella oportunidad "por estar en aquella sazón ocupado en la Casa de la Contratación" en asuntos de la Corona y "no se aver hallado en la corte", y que por ello "fue proveído del dicho oficio de piloto mayor Juan Díaz de Solís", nombramiento que seguidamente había protestado por considerarlo injusto. Sin ocultar su amargura, manifestaba que "ha servido hasta aquí a Nos e a nuestra corona real en cosas de la dicha Casa y que tiene habilidad e suficiencia para servir el dicho oficio de piloto mayor". El rey Fernando, quien no solía dar marcha atrás en sus decisiones, ratificó el nombramiento de Solís, pero quiso compensar a San Martín nombrándolo piloto real y miembro de la Casa de la Contratación. Los sueños del sevillano se desvanecieron como el humo de una hoguera. No obstante, San Martín, confiando en sus

\footnotetext{
${ }^{38}$ ANGLERÍA, Pedro Mártir de. Décadas del Nuevo Mundo. Op. cit., p. 140.

${ }^{39}$ AGI, Contratación, 5784, L.1. MENA GARCIA, Carmen. Conocer y dominar los astros... Op. cit., p. 206.

${ }^{40}$ Consta que el 19 de agosto de 1513 San Martín había sido encargado por los oficiales de la Contratación de cerrar la compra de la Rosa de Santa María, propiedad del maestre paleño Diego Quintero de la Rosa para la flota de Pedrarias en la escribanía de Mateo de la Cuadra MENA GARCIA, Carmen. Sevilla y las flotas de Indias. Op. cit., 292.

${ }^{41}$ MENA GARCIA, Carmen. Sevilla y las flotas de Indias. Op. cit., p. 267 y ss.
} 
cualidades e inasequible al desaliento, vuelve a la carga tras la trágica muerte de Juan Díaz de Solís en el Río de la Plata (enero, 1516), una vez más solicita el puesto, y de nuevo pierde la batalla frente a un duro competidor: se trata de Sebastián Caboto, quien ha sido nombrado Piloto Mayor el 5 de febrero de 1518. Posteriormente alguien señaló al obispo Fonseca y al secretario Conchillos como los responsables de esta derrota ${ }^{42}$.

Un año más tarde San Martín se enfrenta a una nueva batalla, aunque desconoce que será la última. En el caluroso mes de agosto sevillano la flota de Magallanes ultima sus preparativos en el puerto de las Muelas; los marineros apuran el último trago en mesones y tabernas, los mozos de cuerda izan los pesados fardos y los arrumadores los ajustan con precisión milimétrica en las bodegas. Cuando todo parece estar a punto, el piloto sevillano acude a su casa en Santa María la Mayor para despedirse de su familia. A sus padres y hermano -Cristóbal de San Martínencomienda el cuidado de sus dos hijas: Juana y María de San Martín, tan sólo unas niñas que crecen con la familia paterna ante la ausencia de la madre ${ }^{43}$. El piloto ha sido destinado a la nao San Antonio y comparte el gobierno del barco con un marino paleño llamado Juan Rodríguez Mafra. Es el único barco de la flota que lleva a bordo dos pilotos, tal vez porque alguien eligió a San Martín, más por sus dotes cosmográficas que por las de tripulante avezado ${ }^{44}$. Más adelante Joao de Barros lo destacará del resto de la tripulación reconociéndolo como "latinista experto en materias concernientes al mar y la geografía" o más afectuosamente, como "nuestro astrólogo de Sevilla". Y esa parece ser, en efecto, su principal misión ${ }^{45}$.

En ausencia de Ruy Falero, el piloto sevillano se convierte en el cosmógrafo extraoficial del viaje a la Especiería. Sentado cerca del mástil mayor, por medio de su astrolabio -el "buscador de astros" de los Antiguos-, cuadrante, ballestilla, aguja y de sus tablas de declinación solar, toma mediciones a lo largo de la singladura y las va a anotando en hojas de pergamino. Prepara así un precioso Derrotero que luego serviría para demostrar los errores de las tablas astronómicas utilizadas por los navegantes de la época. Tiene en sus manos el Regimiento de Falero para averiguar la longitud, que el cosmógrafo portugués entregó, muy a su pesar, a Magallanes antes de la despedida, y va contrastando sus cálculos ${ }^{46}$. No parecen acertados,

\footnotetext{
42 GIMÉNEZ FERNÁNDEZ, Manuel. Bartolomé de las Casas. Tomo Il: Política inicial de Carlos I en Indias. Sevilla: Escuela de Estudios Hispanoamericanos, 1960, pp. 97-98.

43 MENA GARCIA, Carmen. Conocer y dominar los astros... Op. cit., p. 198.

44 Rolando LAGUARDA TRIAS aventura que San Martín viajaba sólo en calidad de cosmógrafo y Mafra de piloto. Las longitudes geográficas. En: A viagem de Fernão de Magalhães e a questão das Molucas. Actas do II Colóquio luso espanhol de Historia Ultramarina. Lisboa: Junta de Investigaciones Científicas de Ultramar, 1975, p. 154.

45 BARROS, Joao de. Décadas de Asia (1552-1615). Lisboa: Divisao de Publicacoes e Biblioteca Agencia Geral das colonias, 1946. 4 vols, Década III, Lib. V, Cap. X, Vol. III, p. 297.

${ }^{46}$ LAGUARDA TRÍAS, Rolando. Las longitudes geográficas. Op. cit, p. 165. Según la versión del cronista portugués Lopes de Castanheda, estando en este puerto de San Julián, Magallanes "mostrou aos pilotos \& ao astrologo Andrés de Sam Martí ho regimento que leueua de Ruy Faleiro acerca de se poder saber a altura de leste a oeste como a disse. E vindo ho regimento por todos, mandoulhes Fernão de Magalhaes que dissese cada hum o que alcançava a saber... E os pilotos respondeao por escrito que não se podía usar daquele regimento nem aproueitaua pera se navegar por ele... \& ho astrologo respondeu ho mesmo". LAGUARDA TRIAS, Rolando. El cosmógrafo sevillano Andrés de San Martín, inventor de las cartas esféricas. Montevideo: Imprenta Militar, 1991, p. 28.
} 
concluye. Al fondear en la bahía de San Julián ${ }^{47}$, salta a tierra y "con una exactitud impropia para su tiempo", que dejó admirado a Humboldt, averigua el lugar en que se encontraban: " $61^{\circ}$ al oeste de Sevilla $-67^{\circ}$ al oeste de Greenwich- y lo logra con tan sólo un pequeño error de $37^{\prime}$, "una aproximación seguramente irrepetible en la historia de la náutica hasta el uso del cronómetro marino en la segunda mitad del siglo XVIII"48. El cosmógrafo sevillano aprovecha también para tomar la altura del sol y de aquella medida colige la latitud de San Julián: 49 18'Sur. Aquel fue un acontecimiento histórico. Ningún hombre hasta entonces había medido una latitud $\tan$ austral $^{49}$.

Con tintes sombríos se recuerda la presencia del cosmógrafo en aquel puerto de la Patagonia y el duro castigo que le aplicó Magallanes por su participación en el famoso motín de San Julián al decretar que le diesen, hasta tres veces, "tratos de cuerda". No hay testimonio alguno que señale a San Martín involucrado en estocadas y hechos violentos, sólo que provocó la ira del capitán general "porque le hallaron una figura fecha de la navegación que habían llevado e por miedo la había echado a la mar" ${ }^{\prime 50}$. De acuerdo con esta versión, San Martín habría ido volcando en un planisferio todos los datos del derrotero del viaje hasta llegar a la costa patagónica y sospechaba que su actuación iba a disgustar al receloso Magallanes como así fue-, razón por la cual intentó deshacerse del mismo en pleno motín.

El trato de cuerda o garrucha consistía en atar al acusado con las manos a las espaldas y tirando fuertemente de sus muñecas, enlazadas a un cabo, se procedía a izarlo a varios metros de altura. A una señal, se le dejaba caer bruscamente hasta que rozaba el agua. Se trataba de un horroroso suplicio para el reo que solía producir el dislocamiento de los huesos cuando no otras terribles secuelas. A veces, se añadía un elemento de peso para que el cuerpo cayera con mayor violencia y el daño fuera mayor. La sentencia dictada contra San Martín dictaminó que se le colocasen "servidores de lombardas a los pies", a resultas de lo cual "se descoyuntó". Otros testigos aseguraron que "perdió los miembros" ${ }^{2}$. Y, por último, hay quien asegura que ambos relatos exageraban porque de haberse producido tales daños, difícilmente el piloto podría haber continuado al servicio de la flota ni

\footnotetext{
${ }^{47}$ Entre el 31 de marzo, en que la armada entró en el citado puerto, hasta el 24 de agosto de 1520 en que lo abandonó.

${ }^{48}$ CEREZO, Ricardo. Conjetura y realidad geográfica en la primera circunnavegación a la tierra. En: Actas del Congreso de Historia del Descubrimiento. Tomo II. Madrid: Real Academia de la Historia; Confederación española de Cajas de Ahorros, 1992, pp. 167-168. Consta que A. de San Martín implementó una nueva versión del método de Johannes Werner (1514) basado en las distancias lunares. "Observó la posición de la Luna con respecto a Júpiter y del resultado que obtuvo concluyó que estaba seriamente corrompido, cosa que atribuyó a inexactitudes de las tablas astronómicas de Zacuto y Regomontano (tenía razón)." PORTUONDO, María M. Ciencia secreta. La cosmografía española del Nuevo Mundo. Madrid: Iberoamericana-Vervuert, 2013, p. 254.

49 LAGUARDA TRIAS, Rolando. El cosmógrafo... Op. cit., Apéndice 1. También del mismo autor: LAGUARDA TRÍAS, Rolando. Las longitudes geográficas. Op. cit, pp. 135-178. COMELLAS, José Luis. La primera vuelta al mundo. Madrid: Rialp, 2012, p. 84.

${ }^{50}$ AGI, Patronato, 34, R.15. Carta de Juan López de Recalde al obispo Fonseca. Sevilla, 12, mayo, 1521. Fue publicada por FERNÁNDEZ DE NAVARRETE, Martín en su Colección de los viajes y descubrimientos que hicieron por mar los españoles desde fines del siglo XV. BAE, tomo LXXVI, vol. II. Edición y estudio preliminar de Carlos seco Serrano. Madrid: Atlas, 1964, pp. 528-532.

${ }^{51}$ AGI, Patronato, 34, R.14. Carta de Sancho de Matienzo y Juan López de Recalde al rey. Sevilla, sd, mayo, 1521.
} 
haber bajado a tierra para tomar sus mediciones astronómicas ${ }^{52}$.

Rolando Laguarda Trías atribuye a Andrés de San Martín la autoría del mapa de las islas Sansón y de los Gigantes (archipiélago de las Malvinas) que debieron ser descubiertas por los tripulantes de la nao San Antonio el 20 de julio de 1520 en una exploración por las aguas aledañas, mientras el resto de la flota de Magallanes invernaba en San Julián. Lo más interesante de este asunto es que no se trata de una carta plana o cuadrada, con los mismos valores en longitud y latitud, propias de aquella época de navegación a estima, sino de una novedosa proyección esférica. En definitiva -concluye el citado autor- "se puede afirmar que Andrés de San Martín inventó las cartas esféricas de navegar...una portentosa innovación en 1520, es decir, casi medio siglo antes de que Mercator diera a conocer su mapamundi esférico (1569)"

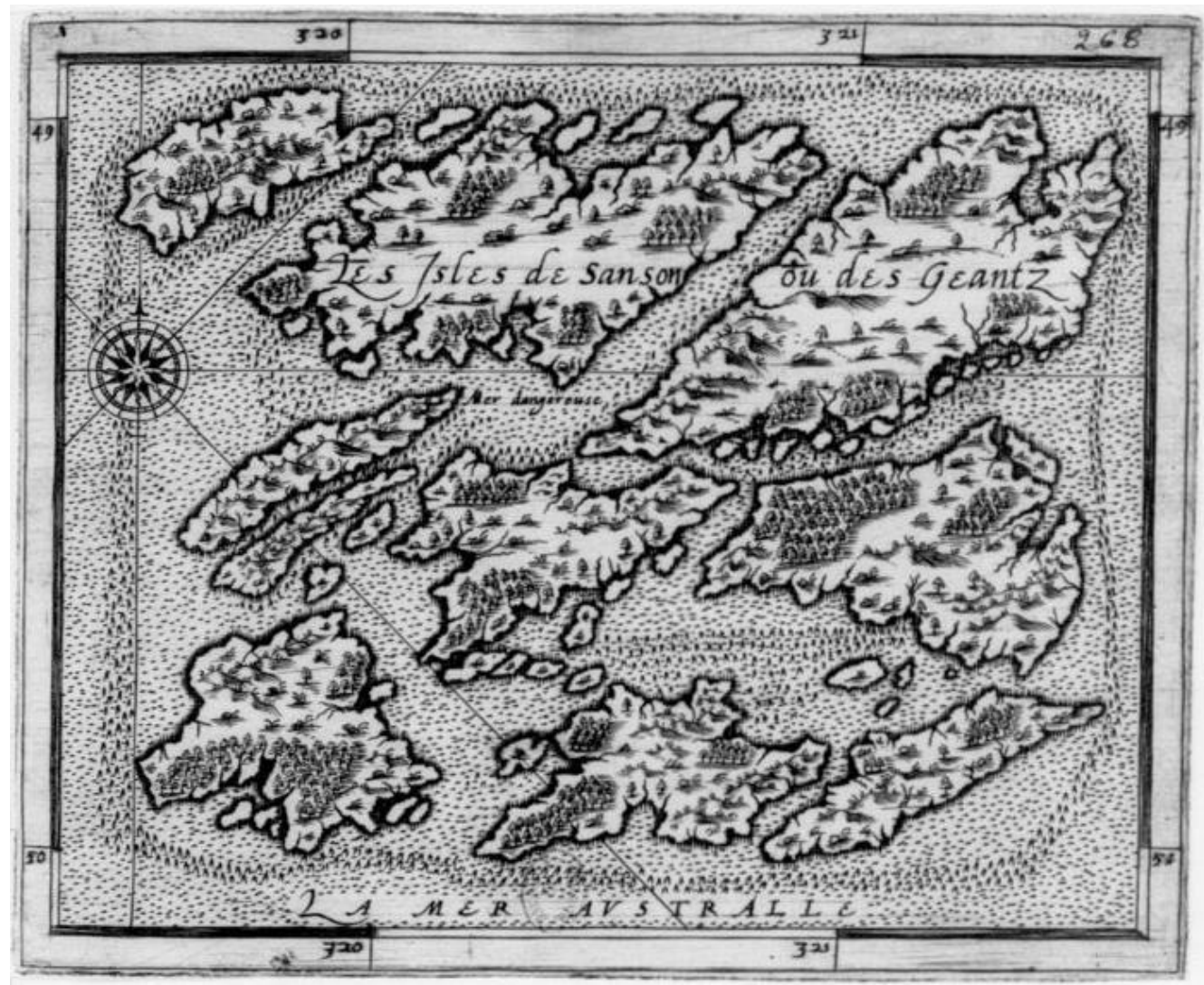

Fig. 1: Mapa manuscrito en francés de André Thevet (1586) de dos islas que han sido identificadas con las Malvinas. Fuente: CAVIGLIA, Sergio Esteban ${ }^{54}$.

\footnotetext{
${ }^{52}$ MENA GARCIA, Carmen. Conocer y dominar los astros... Op. cit., p. 221, citando a FERNÁNDEZ DE NAVARRETE, Martín. Colección de los viajes... Op. cit., p.529.

${ }^{53}$ LAGUARDA TRIAS, Rolando. El cosmógrafo... Op. cit., p. 20. El autor supone que fue Álvaro de la Mezquita, el primo de Magallanes y capitán de la San Antonio, quien debió consultar en Lisboa los libros de rotear de San Martín, que habían sido confiscados por los portugueses en las Molucas, sacando copia de los mismos. Considera también como probable que fuera Mezquita quien entregó personalmente el mapa de las islas de Sansón y de los Gigantes al franciscano André Thevet, quien lo dio a conocer en su obra Le grand insulaire et pilotage (1586).

${ }^{54}$ Biblioteca Nacional de Francia. Rolando Laguarda Trías consideró que este mapa es una copia de otro realizado hacia 1520 por el piloto y cosmógrafo español Andrés de San Martín. CAVIGLIA, Sergio Esteban. Malvinas: Soberanía, Memoria y Justicia: 10 de Junio de 1829 [en línea]. Ministerio de
} 
Más adelante, tras el motín de San Julián y el descabezamiento de los mandos de la flota, Magallanes ordena a San Martín que embarque en la Victoria. El barco navega ahora a las órdenes del portugués Duarte de Barbosa y tras muchas penurias y vicisitudes alcanza las aguas de Indonesia. Sin saberlo, San Martín acorta sus días conforme los barcos se acercan a las Molucas, propósito y objetivo del durísimo viaje. Las bajas se siguen produciendo. El 27 de abril de 1521, en Mactán, Magallanes fue asesinado por los indios, y el 1 de mayo en Cebú, desaparecieron Andrés de San Martín y otros veintiséis compañeros que, confiados, aceptaron la invitación del reyezuelo Humabón, cayendo en una trampa mortal.

¿Quiere esto decir que San Martín fue una de las víctimas del famoso y traicionero convite? Esta ha venido siendo la versión oficial, tan oficial como la lista de muertos y desaparecidos que Juan Sebastián del Cano trajo consigo de regreso a Sevilla. Pero la incógnita sobre su muerte siguió sin despejarse aún después de muchos años. Algunos de los supervivientes dijeron que el cosmógrafo perdió la vida por excederse en el cuidado de su higiene. Nunca se había conocido cosa igual. Pero lo cierto es que algunos declararon haber visto por última vez a San Martín cuando bajaba a tierra a lavar su ropa, y que "nunca paresçió más", otros, como el piloto portugués Esteban Gómez, especificaban que salió en una isla "a lavar unas camisas e que allí se quedó" 55 . Tanta incertidumbre alentó durante muchos años las esperanzas de la familia de San Martín de que éste siguiera aún con vida. En 1535, cuando ya habían transcurrido catorce años de la desaparición, su hermano Cristóbal pleiteaba ante el Consejo de Indias declarando que "hasta oy no se sabe dél si es bivo ni muerto" ${ }^{\prime 5}$. También los amigos, los verdaderos amigos como Juan Sebastián del Cano, asimismo "entendido e interesado en astrología"57, confiaban en encontrarlo algún día en cualquier isla del Pacífico. Así se desprende de estas mandas del testamento del famoso maestre vasco, dictado a las puertas de la muerte, el 26 de julio de 1526, en el que legaba al cosmógrafo sevillano, por si "toparen con él", algunos de sus objetos más preciados, en un gesto realmente conmovedor, tales como "tres varas de paño colorado de Londres" y dos libros de astrología, entre ellos un almanaque en latín ${ }^{58}$.

Los papeles de San Martín, sus preciosas anotaciones cosmográficas, cayeron finalmente en manos de los portugueses cuando la Trinidad y sus tripulantes fueron capturados en Ternate (Molucas). El factor Resendez se los llevó a Lisboa. Allí pudo consultarlos, entre otros, el cronista portugués Joao de Barros y el español Antonio de Herrera. Actualmente se ignora su paradero.

Educación de la Provincia de Chubut, 2012, pp. 52-53. Disponible en $<$ https://commons.wikimedia.org/wiki/File:Primer mapa de las Islas Malvinas (1520) por Andr\%C3 $\%$ A9s de San Mart\%C3\%ADn.jpg >.

${ }^{55}$ MENA GARCIA, Carmen. Conocer y dominar los astros... Op. cit., p. 228.

${ }^{56}$ AGI, Justicia, 1152, N.1, R.2. Pleito fiscal: Andrés de San Martín, 1534-11-6/1535-3-3.

${ }^{57}$ Sobre la relación entre Elcano y San Martín, cfr. PÉREZ DE TUDELA BUESO, Juan. La Especiería de Castilla. En: A viagem de Fernão de Magalhães...Op. cit., pp. 656-657.

${ }^{58}$ AGI, Patronato, 38, R.1. Véase el exhaustivo estudio de ROMERO TALLAFIGO, Manuel. EI testamento de Juan Sebastián Elcano (1526). Palabras para un autorretrato. Sevilla: Editorial Universitaria de Sevilla, 2021; en especial el cap. XIV: "Elcano, lector. Los libros del cosmógrafo Andrés de San Martín". 
"...del cual (Gonzalo de Espinosa) -dice Barros- yo tuve algunos papeles que le pertenecían, entre los cuales estaba un libro hecho por él de todo aquel viaje; y así tuve otros papeles y libros que Duarte de Resende, factor del Maluco, recogió del astrólogo Andrés de San Martín, porque como era latino y hombre estudioso de las cosas del mar y de geografía, entendió luego en ellos; y venido a este Reino (de Portugal) tuvimos de él algunos, principalmente un libro que este Andrés de San Martín escribió de su mano, en el cual está el discurso del camino que hizo y de todas sus alturas, observaciones y conjunciones que tomó" ${ }^{2}$.

${ }^{59}$ BARROS, Joao de. Décadas de Asia... Op. cit., III Década, Lib. V, Cap. IX y X. 


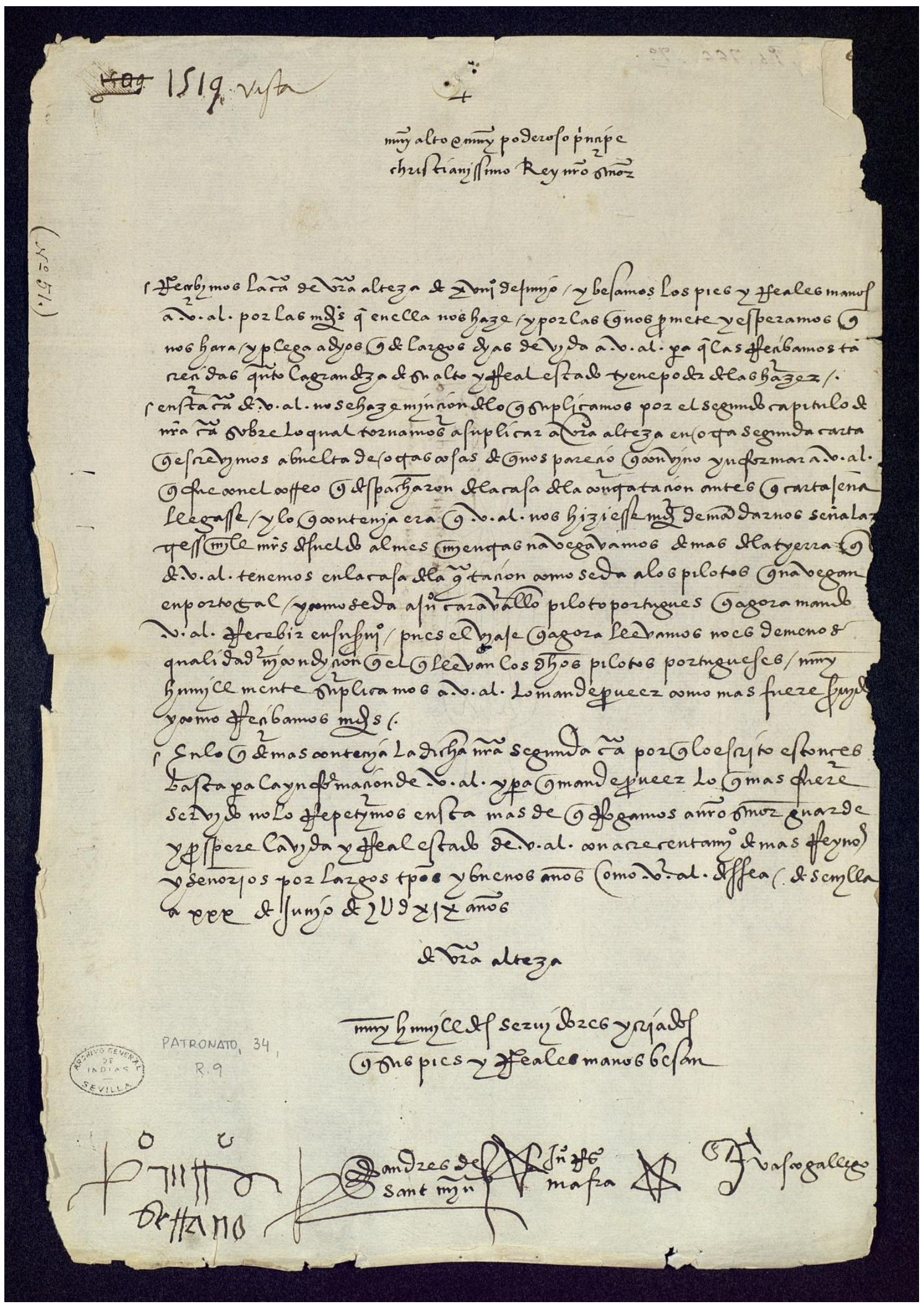

Fig. 2: Carta de los pilotos reales de la flota de Magallanes, solicitando un aumento de sueldo de 3.000 maravedís mensuales, como cobraban los pilotos de Portugal y el mismo Carvallo, mientras durase el viaje a la Especiería. Fuente: AGI, Patronato, 34, R.9.

${ }^{60}$ AGI, Patronato, 34, R.9. Carta de los pilotos reales de la flota de Magallanes, solicitando un 


\section{Juan Rodríguez Mafra, alias “Juan Barbero"}

En el verano de 1519 muy pocos podían rivalizar en experiencia marinera con Juan Rodríguez Mafra, el hermano de Diego de Lepe ${ }^{61}$ y sobrino de los Pinzones. Desde que el piloto de Palos acompañó a Colón en su segundo viaje (1493) había atravesado el océano y avistado nuevas tierras en numerosas ocasiones ${ }^{62}$. Más de treinta años avalaban su experiencia como maestre y piloto, ya sea participando en viajes exploradores - a veces como armador de la flotilla- en acciones militare ${ }^{63}$, o bien transportando pasajeros y mercancías a las islas antillanas ${ }^{64}$.

Para 1510 su fama de experto marino ya debía ser grande pues hasta los portugueses se interesaron por él. En aquellos momentos en el vecino reino de Portugal se organizaba una flota para explorar las tierras descubiertas en las Indias, años atrás, por Juan Díaz de Solís y buscaban pilotos conocedores de aquella singladura. Hasta Castilla se desplazó Juan Álvarez, un enviado del monarca portugués, con la sigilosa misión de reclutar al piloto paleño, también conocido con el apodo de Juan Barbero, quién sabe por qué curiosa razón: "porque él mismo ha dicho y confesado que él había venido de Portugal a hablar con un Juan Barbero, piloto, que ansy mismo se llama Juan Rodríguez de Mafra por otro nombre, a le rogar que fuese allá a Portugal"65. Teniendo en cuenta lo duro que resultaba ganarse la vida en el mar, ¿qué marino haría ascos a un puñado de monedas de oro? En efecto, Mafra cayó en la tentación y aceptó una bolsa con 20 ducados que el portugués puso en sus manos como adelanto por su servicios, aunque más tarde el piloto se arrepintió y buscó un lugar seguro donde ocultarse para que nadie pudiera encontrarlo. ¿Denunció Mafra al espía portugués ante los oficiales de la Contratación? Es razonable. Lo prueba el hecho de que Juan Álvarez fue apresado y dio con sus huesos en la cárcel, provocando un auténtico conflicto diplomático entre

aumento de sueldo de 3.000 maravedís mensuales, como cobraban los pilotos de Portugal y el mismo Carvallo, mientras durase el viaje a la Especiería. Sevilla, 30 de junio de 1519. Al pie del documento estampan su firma Juan Rodríguez Serrano y Andrés de San Martín. Por el ductus de la letra de San Martín, intuyo que es este mismo quien firma en lugar de sus colegas Juan Rodríguez Mafra y Vasco Gallego, de quienes se conoce que eran analfabetos. Ambos solo son capaces de enmarcar sus nombres con sendos garabatos: Mafra, dos estrellas de cinco puntas y Gallego, un signo indescifrable.

${ }^{61}$ GIL FERNÁNDEZ, Juan. Marinos y mercaderes en Indias. Anuario de Estudios Americanos. 1985, n. 42 , p. 19.

62 No quiso acompañar a Colón en su primer viaje "por lo tener por cosa vana". ORTEGA, OFM. P. Ángel. La Rábida. Historia documental y crítica. Vol. II. Sevilla: Imprenta de San Antonio, 1925, p. 144. ${ }^{63}$ Consta que en 1505 cuando se disponía a realizar un viaje a las Indias, fue enviado a la toma de Mazalquivir como maestre de la carabela Santa Cruz. ORTEGA, OFM. P. Ángel. La Rábida... Op. cit., vol. III, p. 144. En 1506 pilota la nao Santa Catalina. Así lo atestigua el siguiente registro notarial: "Pedro de Jerez, cambiador, vecino de Sevilla en la collación de San Idelfonso, otorga poder a Miguel Sánchez, piloto de la nao Santa María de la Luz para que cobrase a Alonso Cota, maestre de la nao Santa Catalina, vecino de Palos, a Diego Fernández de Ribera, mercader y a Juan Rodríguez Mafra, piloto de la dicha nao, vecino de la citada villa de Palos, 150 ducados que le adeudaban". Libro de 1506. Oficio IV. Libro III. Escribanía de Francisco de Segura. Folio 448, Fecha 18 de septiembre. CAPS, tomo VII, Sevilla, 1990, p. 111.

${ }^{64}$ El P. Ortega se hace eco de otro viaje realizado por Mafra en 1512 a la isla de Cuba, pilotando la nao Santa Cruz. No debió ser el único. ORTEGA, OFM. P. Ángel. La Rábida... Op. cit., vol. III, p. 144.

${ }^{65} \mathrm{AGI}$, Indiferente, 418, L.2. Real Cédula a Alonso de la Puente, contino de la Casa Real, sobre lo que ha de decir al rey de Portugal. S.f. (probablemente de 1510). AGI, Indiferente, 418, L.2. Orden a los oficiales de la Casa de la Contratación. Madrid, 18, diciembre, 1510. 
España y Portugal, mientras que al piloto sobornado no se le sometió a ningún proceso judicial. Por el contrario, dos años más tarde Mafra fue distinguido con el título de piloto de Su Alteza por Real Cédula dada en Burgos el 23 de mayo de $1512^{66}$.

Cuando se dispone a navegar junto a Andrés de San Martín en la nao San Antonio, Juan tiene ya 49 años o está a punto de cumplir los $50^{67}$. Le acompaña su hijo Diego al que ha enrolado como paje dada su corta edad. Piensa que aunque es todavía pequeño para arrebatárselo a su madre, necesita labrarse un futuro y en su familia -los Pinzones- no se conoce mejor oficio que el de marinero. Mantiene fuertes vínculos afectivos con sus parientes de Palos, que ya han echado raíces a uno y otro lado del océano, y antes de embarcarse en la flota de la Especiería escribe al monarca preocupándose por la situación económica de "las mujeres e hijos de ciertos parientes suyos que murieron en las Indias... y "que al tiempo que murieron dejaron heredades, casas y otras cosas empeñadas y los acreedores se las quitan y venden" ${ }^{\text {"68 }}$. También se afana por conseguir el reconocimiento de los Pinzones y encabeza la petición ${ }^{69}$ de un escudo de armas familiar que el monarca otorga en Barcelona, el 23 de septiembre de 1519, cuando ya la flota ha abandonado Sanlúcar de Barrameda: "por la presente vos hacemos merced e queremos que podáis tener e traer por vuestras armas conocidas tres carauelas al natural en la mar e de cada una ellas salga una mano mostrando la primera tierra que así fallaron e descubrieron en un escudo tal como este ... e por orla del dicho escudo podays traer e trayays unas ancoras e unos coraçones las quales dichas armas vos damos...".

Juan Rodríguez Mafra, el experto marino, no llegó a disfrutar de ese escudo de armas, concedido cuando ya surcaba el océano. Por lo que respecta al viaje que dio la vuelta al mundo, el último de su carrera como marino, apenas ha quedado huellas de su presencia. En el motín de San Julián, permaneció fiel a Magallanes y logró salir indemne y reforzado ${ }^{70}$. En algún momento del viaje pasó a pilotar la Concepción, antes de que el barco fuera pasto de las llamas. Tuvo la mala fortuna de morir, probablemente a causa del escorbuto, un jueves, 28 de marzo de 1521, cuando la flota ya había alcanzado Butuán (al norte de la isla de Mindanao). Una escueta nota de la lista de fallecidos recogía el suceso: "este mismo día (murió) Juan Rodríguez Mafra, piloto de la Concepción, de enfermedad"

\footnotetext{
${ }^{66} \mathrm{AGI}$, Indiferente, 420, L.8.

${ }^{67}$ En la probanza de 15 de febrero de 1515, estando en Cuba, declaró tener 45 años de edad. ORTEGA, OFM. P. Ángel. La Rábida... Op. cit., vol. III, p. 144.

${ }^{68} \mathrm{AGI}$, Indiferente, 420, L.8. Real Cédula a la Chancillería de Granada. Barcelona, 14, septiembre, 1519.

${ }^{69}$ AGI, Indiferente, 420, L.8. "Por quanto por parte de vos Johan Rodríguez Mafra, nuestro piloto e Ginés Muñoz, nuestro capellán e Diego Martín Pinçon e Alvaro Alonso, notarios, e Johan Pinçon e Alonso Gonçalez, vecinos e naturales de la villa de Palos..." Escudo de armas concedido por Carlos I a los primeros descendientes de los Pinzón. Barcelona, 23, septiembre, 1519.

${ }^{70} \mathrm{Da}$ buena prueba de ello el hecho de que Magallanes lo seleccionara entre sus testigos para declarar en el proceso abierto por éste sobre lo sucedido en el motín de San Julián. "Información que mandó tomar Magallanes en el puerto de San Julián, 26, abril, 1520". Lo publica FERNÁNDEZ DE NAVARRETE, Martín. Colección de los viajes... Op. cit., apéndice XX.

${ }_{71}$ AGI, Patronato, 34, R.11. Relación de las personas que han fallecido en la armada que el emperador Nuestro Señor envió al descubrimiento de la especiería de la cual era Capitán General
} 
En la Casa de la Contratación se presentaba el 26 de noviembre de 1525 Catalina Rodríguez, hija y heredera de Juan Rodríguez Mafra, "difunto que Dios aya, piloto que fue de Sus Magestades" para cobrar de los oficiales 20.000 maravedís que aún restaban por liquidar de su salario, desde agosto de 1520 hasta fin de abril de 1521 "que el dicho Juan Rodríguez de Mafra falleció"72.

\section{Vasco Gallego y su hijo Vasquito}

Como Esteban Gómez o Carvallo, el piloto Vasco Gallego también era portugués, y más concretamente de Lisboa. Estaba casado con Margarida Hernández con la que tenía dos hijos llamados Francisco Andero y Vasco Gallego ${ }^{73}$ y antes de engancharse en la aventura magallánica residía en el marinero barrio de Triana. No se sabe en qué momento el piloto lisboeta decidió afincarse en Sevilla, pero es probable que para 1516 contemplase su futuro definitivamente al servicio del rey de España y no del de Portugal. Lo prueba el hecho de que ya entonces hubiera decidido desprenderse, utilizando como intermediario al hijo de ambos Francisco Andero, de la casa familiar que el matrimonio poseía en Lisboa, en la Cordonería Vieja, feligresía de Santa María de los Mártires. Buena prueba de que no pensaba regresar $^{74}$.

Para cubrir las últimas vacantes producidas en la plantilla de la Casa de la Contratación, Vasco Gallego había sido nombrado piloto de Sus Altezas el 12 de julio de $1514^{75}$, al mismo tiempo que el moguereño Andrés García Niño, y es probable que para entonces ya llevase varios años instalado en Andalucía. La primera misión oficial de la que forma parte es la conocida como la armada contra los caribes, que dirige en mayo de 1515 Juan Ponce de León, fundador de Puerto Rico y Adelantado de la Florida ${ }^{76}$. Interesado por las numerosas oportunidades que brindaba el comercio atlántico, lo encontramos muy pronto compaginando su profesión de tripulante de barco con la de mercader indiano, cosa muy frecuente entre la gente de mar. Y así en la primavera de 1515, antes de zarpar con Ponce de León, acude a la notaría de Bernal González Vallesillo y otorga un poder a un tal Diego Rodríguez "para que cobre cuanto al otorgante se le debiere y para que se haga cargo de cuántas mercaderías vinieran consignadas para él de las Indias" "77. Probablemente

\footnotetext{
Fernando de Magallanes, 1525.

${ }^{72}$ AGl, Contratación, 4675B, Lib. 4.

${ }^{73}$ Orden de pago a Margarida Hernández, esposa del piloto Vasco Gallego, año 1526. AGI, Contratación, 4675B, L.4.

${ }^{74}$ Poder notarial de Vasco Gallego y Margarida Fernández a su hijo Francisco Dandero, estante en la corte del rey de Portugal. Libro de 1516. Oficio I, Libro II, Escribanía de Mateo de la Cuadra. Fecha, 2, octubre. Catálogo de los Fondos Americanos del Archivo de Protocolos de Sevilla. Tomo IV. Sevilla: Instituto Hispano Cubano, 2002.

${ }^{75} \mathrm{AGI}$, Contratación, 5784, fol. 21.Nombramiento de piloto a Vasco Gallego con 30.000 maravedís de salario al año, firmado en Segovia, 12, julio de 1514.

${ }^{76}$ AGI, 4675B, L.2. Citado en LADERO QUESADA, Miguel Ángel. Las Indias de Castilla en sus primeros años. Cuentas de la Casa de la Contratación (1503-1521). Madrid: Dykinson, S.L., 2008, p. 415. En los libros de la tesorería de la Contratación de 1515 consta el abono a Vasco Gallego de 10.000 maravedís por el tercio primero de su quitación del citado año y 15.000 más por el salario de seis meses adelantados "los quales se le libraron porque va en servicio de Su Alteza con Juan Ponce de León en el armada contra los caribes".

77 Libro año 1515. Oficio XV. Libro II. Fecha 21 de Mayo. Catálogo de los Fondos Americanos del Archivo de Protocolos de Sevilla... Op. cit., Tomo X. Sevilla, Instituto Hispano Cubano, 1997.
} 
de este viaje contra los caribes, supuestamente antropófagos, que asolaban la isla de Puerto Rico, proceda su relación con el mercader Juan de la Feria, vecino de San Juan, quien en 1517 declara haber contraído una deuda con el piloto de hasta 30 ducados de oro $^{78}$. Tal y como se deduce de los registros notariales de estos años, el marino también se interesa por el negocio del estaño y en comandita con su socio Bartolomé de Tapia obtienen de Tomás Mallart, un mercader inglés bien activo en el mercado hispalense, más de 14 arrobas del citado metal por 26.357 maravedís, aunque se desconocen más detalles sobre la operación.

Bien, por lo que puede apreciarse, Vasco Gallego no desaprovecha su tiempo. Ahora, en 1518, ha recibido órdenes de los oficiales de la Casa de la Contratación de que debe incorporarse a la expedición comandada por Magallanes a las islas Molucas y lo hace en compañía de su hijo Vasquito, un niño al que su padre ha decidido enrolar como paje en su mismo barco -la Victoria- para que se forje como marino. Dada su corta edad, el pequeño Vasquito embarcaba feliz dispuesto a vivir una increíble aventura, pero no podía imaginar la pesadilla que le aguardaba. Su padre falleció a bordo de la Victoria, "de enfermedad" -presumiblemente de escorbuto- un 28 de febrero de 1521, durante la larga y desoladora travesía del Pacífico. Tuvo tiempo de dictar su última voluntad al escribano Sancho de Heredia y de encomendar a sus compañeros que cuidaran de su hijo Vasquito ${ }^{79}$. Sin duda lo hicieron bien, pues a pesar de todas las penalidades el niño logró sobrevivir. En el regreso de la Victoria con Juan Sebastián del Cano, Vasquito y otros doce hombres tuvieron la mala fortuna de ser capturados por los portugueses en Cabo Verde. En esta ocasión Carlos $\mathrm{V}$ intervino rápidamente, solicitando al rey de Portugal la liberación de los prisioneros, entre ellos Vasquito, que ya había ascendido al puesto de grumete. Aunque ya había crecido en edad y en experiencia, para su madre seguía siendo un niño, por eso, a su regreso, fue ella la que se personó en la Casa de la Contratación para cobrar el salario del hijo aventurero ${ }^{80}$.

\section{Juan López Carvallo, un Magallanes sin grandeza}

El portugués Juan López Carvallo embarcó como piloto de la nao Concepción por recomendación expresa del capitán Magallanes. Cuando dieron comienzo los preparativos, en una de sus entrevistas con Carlos V, Magallanes le comentó al monarca que "él sabía de una persona que es buen piloto y bien hábil para lo susodicho (el viaje a la Especiería)". Muy sólidos debieron de ser los argumentos del capitán pues el rey consintió en ello, dando orden, el 17 de abril de 1518, a los oficiales de la Contratación de que examinaran al piloto portugués. Magallanes advirtió de paso al monarca de que Carvallo sólo aceptaría el puesto si se le asignaba, además de su salario anual, un extra de otros 3.000 maravedís por cada mes de navegación ${ }^{81}$. Era una costumbre ya establecida entre los pilotos que navegaban al servicio del rey de Portugal, y Carlos V tuvo a bien consentirlo.

\footnotetext{
${ }^{78}$ Libro año 1517. Oficio XV. Libro I. Fecha 5 de Mayo. Catálogo de los Fondos Americanos del Archivo de Protocolos de Sevilla... Op. cit., Tomo X. Sevilla, Instituto Hispano Cubano, 1997.

${ }^{79}$ AGI, Patronato, 34, R.11. Relación de personas que han fallecido en la armada, 1525.

${ }^{80}$ AGl, Contratación, 4675B, Lib. 4.

${ }^{81} \mathrm{AGI}$, Indiferente, 420, Lib. 8. Real Cédula a los oficiales de la Contratación. Aranda, 17, abril, 1518.
} 
Apenas se conservan noticias de Carvallo con anterioridad a este viaje a las Molucas, pero es seguro que ya había navegado a las Indias. Él mismo confesó a Pigafetta que había vivido cuatro años en Brasil donde dejó un hijo habido con una india. Por ese motivo, al aproximarse a las costas del Brasil ${ }^{82}$, Carvallo rogó a Magallanes que fondeasen en una bahía ("Bahía de Enero") para recoger a su vástago mestizo ${ }^{83}$. Deseaba llevarlo consigo en aquel viaje. Es fácil imaginar lo que debió sentir esa madre cuando el portugués se lo arrebató de sus brazos, ya para siempre.

Sin embargo, Carvallo no resultó tan buen marino, como esperaba Magallanes, ni tampoco conocía tanto las costas americanas como había alardeado. Prueba de ello es que a punto estuvo de encallar su barco, la Concepción, lo que hubiera supuesto la pérdida temprana de uno de los navíos y quién sabe si de toda la flota ${ }^{84}$. Transcurrido algún tiempo, el contador Juan López de Recalde en una carta al obispo de Burgos recordaba aquellos sucesos. Informó a Fonseca que cuando la armada arribaba a las costas del Brasil, Magallanes "dio cargo (de la flota) a Juan López Caraballo, dándole el farol de la nao Concepción para que tirase el camino la costa adelante, el cual diz que se allegó tanto a tierra una y dos veces que si no fuera por Esteban Gómez, que iba con el dicho Magallanes, hubieran dado al través en la costa"85. El piloto Esteban Gómez, mucho más hábil y diestro que Carvallo, los había salvado de un desastre.

Ahora bien, la figura del recomendado piloto adquiere especial protagonismo a partir de la muerte del capitán Magallanes y de los dos capitanes que luego le sucedieron en la jefatura de la flota: Duarte Barbosa y Juan Rodríguez Serrano. La despiadada actuación de Carvallo en el convite traicionero del rey de Cebú, negándose a rescatar a su "compadre" Juan Rodríguez Serrano, mientras éste imploraba a voces desde la playa su ayuda, impactó a todos los testigos de aquel momento. No era posible olvidar aquella tremenda escena. Puestos a indagar en los sentimientos que anidaban su alma, no se descarta la posibilidad de que Carvallo actuó de esta manera porque ansiaba la jefatura, que quedaría libre tras la muerte de Rodríguez Serrano. Desde luego no había mucho donde elegir porque para entonces todos los mandos habían muerto. Lo cierto es que a partir de entonces toda la responsabilidad de aquella aventura recayó sobre los hombros del piloto portugués, ahora al frente de la Trinidad, mientras que el alguacil Gonzalo Gómez de Espinosa, asumía la capitanía de la Victoria.

\footnotetext{
82 "Llamado así por el palo que de allí se traía" (palo brasil). Relación de Ginés de Mafra. En: La primera vuelta al mundo. Madrid: Ediciones Miraguano-Polifemo, 2018, p. 146. El palo brasil fue muy apreciado en toda Europa y uno de los artículos de intercambio comercial más buscado. De esta especie arbórea se extraía un tinte rojo y brillante.

${ }^{83}$ Se desconoce exactamente la edad del pequeño. De 10 años de edad, dice Martín de Ayamonte; un niño de 7, anota Ginés de Mafra.

${ }^{84}$ Max justo GUEDES justifica el "despiste" del piloto Carvallo en razón de la contracorriente y el régimen de vientos que azotan las costas brasileñas entre San Agustín y Cabo Frío. A Armada de Fernão de Magalhães e o Brasil. En: A viagem de Fernão de Magalhães e a questão das Molucas. Actas do II Colóquio luso espanhol de Historia Ultramarina. Lisboa: Junta de Investigaciones Científicas de Ultramar, 1975, p. 365.

${ }^{85}$ AGI, Patronato, 34, R.18. Carta del contador Juan López de Recalde al obispo de Burgos. Sevilla, 12, mayo, 1521. Publicada en: FERNÁNDEZ DE NAVARRETE, Martín. Colección de los viajes... Op. cit., Doc. XXI, p. 529.
} 
Nadie explica los motivos de su elección, pero todos reconocen que fue un error porque su mandato recordaba muchos de los defectos de Magallanes. Juan Sebastián del Cano denunció más tarde que "después de muerto el dicho Magallanes, Juan Caraballo hasia lo que quería”. Mientras que el tripulante Francisco Albo, extendiéndose más en su valoración sobre el piloto portugués, denunció que "mientras Carvallo fue capitán no hizo tesorero ny capitán ny contador ny sabe lo que hazia de los rescates porque ello hazia syn dar parte a nynguno" 86 . Como se deduce de su deplorable actuación, Juan de Carvallo resultó "un Magallanes sin grandeza". A la postre se reveló como "un jefe demasiado preciado de su mando y ensombrecido por la cobardía, la inmoralidad y la avaricia". En definitiva y como alguien ya señaló, "estas feas cualidades le desprestigiaron y le hicieron antipático ante todos, absolutamente todos, sus subordinados" ${ }^{87}$.

La desgraciada actuación de Carvallo en los sucesos acaecidos el 29 de julio de 1521, mientras la flotilla permanecía anclada en la bahía de Borneo (Brunei), fue la gota que colmó el vaso. Según cuenta Pigafetta, el rajá musulmán, orondo y ceremonioso, invitó a los cristianos a visitar su corte a lomo de elefantes. Una delegación compuesta por Juan Sebastián del Cano y Gonzalo Gómez de Espinosa, a los que acompañaban dos marineros griegos y el hijo brasileño de Carvallo bajó a tierra siendo recibidos con gran boato y hospitalidad por el reyezuelo, si bien fueron retenidos allí durante más de quince días ${ }^{88}$ :

"Pasados doce días que aquella gente que habían enviado a la ciudad no venían, como está dicho, los de las naos estaban muy acongojados por ellos, pareciéndoles haberlos perdido ya para siempre" ${ }^{\prime 89}$.

Un buen día, mientras los tripulantes, cada vez más nerviosos, aguardaban en los dos navíos el regreso de sus compañeros se vieron asaltados de improviso por un enjambre de barcos y piraguas. Se trataba de una gran flota dirigida por el capitán general del rey de la isla de Luzón (Filipinas) que regresaba de la conquista de la ciudad de Laoet. La flotilla española -ya de tan sólo dos barcos- temiendo ser capturada se abrió paso a lombardazos y en su huida se apoderó de paños de seda, porcelana y otros objetos valiosos, tomando preso a varios tripulantes, entre los cuales se encontraba el citado capitán de los gentiles. Se trataba de un rehén de extraordinario valor por tratarse del mismísimo hijo de rey de Luzón, que había llegado a Borneo para casarse con la hija del rajá Siripada, y que podría haber sido utilizado como intercambio por los cristianos que permanecían en tierra, retenidos

\footnotetext{
${ }^{86}$ AGI Patronato, 34, R.19. Información recibida por el alcalde de casa y corte, Santiago Díaz de Leguizamo en que declaran el capitán de la nao "Victoria" Juan Sebastián de Elcano, Francisco Albo y Fernando de Bustamante, sobre distintos pormenores del viaje de la primera vuelta al mundo.18, octubre, 1522.

${ }^{87}$ MELÓN Y RUIZ DE GORDEJUELA, Amando. Magallanes-Elcano o la primera vuelta al mundo. Zaragoza: Ed. Luz, 1940, p. 162.

${ }^{88}$ Esto cuenta Ginés de Mafra en su Relación. Pigafetta, por el contrario, dice que Juan Sebastián del Cano y Gómez de Espinosa sólo permanecieron dos días en tierra y luego regresaron. Adviértase que las informaciones que se conservan sobre estos sucesos, entre las que se incluyen las declaraciones de los propios testigos de aquellos hechos, son muy confusas e incluso se contradicen entre sí. Véase también AGI Patronato, 34, R.19. Información recibida por el alcalde de casa y corte Santiago Díaz de Leguizamo, 1522.

${ }^{89}$ Relación de Ginés de Mafra. En: La primera vuelta al mundo. Op. cit., p. 177.
} 
por el rajá.

Carvallo que parecía más interesado en su propio lucro que en el destino final de sus compañeros, sin pensárselo dos veces, decidió liberar al hijo del rey de Luzón, después de hacerse con un sustancioso rescate. Así lo expresaba Pigafetta:

"Juan Carvajo, nuestro piloto, sin advertírnoslo, le puso en libertad cohechado, como después supimos, por una fuerte suma de oro que le prometió..."90.

Pese a ello, Elcano y Espinosa fueron por fin liberados y pudieron regresar a las naos. Cuando se encontraron con los suyos les contaron que los dos marineros griegos $^{91}$ habían decidido quedarse en tierra voluntariamente. Así lo registró el escribano en el rol de fallecidos y ausentes durante la expedición:

"En 15 de julio de 1521 estando las naos Trinidad e Vitoria surtas en el canal de Burney, cerca de la çibdad de Burney se fueron e ausentaron de la dicha nao Vitoria:

- Juan Griego

- Mateo Griego, marineros de la dicha nao Vitoria que se fueron con los moros a la çibdad de Burney".

Respecto al pequeño hijo de Carvallo, dijeron que lo daban por muerto ${ }^{92}$, aunque no habían visto lo uno ni lo otro porque, según confesaron, durante el confinamiento los habían mantenido separados ${ }^{93}$.

Además de los marinos griegos, consta que otros dos tripulantes que habían bajado a tierra para comerciar con los indios se quedaron en Borneo, "no por su voluntad" sino porque la flota zarpó dejándolos atrás. Se trataba de Domingo Barruti, "marinero e escribano que al presente era de la nao Trinidad" y Gonzalo Hernández, "hombre de armas". Atrás quedaba también el hijo mestizo de Carvallo, sobre cuya mezquina conducta sentenciaba Pigafetta: "Así fue castigado Carvajo con la pérdida de su hijo (que nació durante su estancia en Brasil) que hubiera recobrado, sin duda,

${ }^{90}$ PIGAFETTA, Antonio. Primer Viaje en torno al globo... Op. cit, p. 129. AGI, Patronato,34, R.19. Información recibida por el alcalde de casa y corte, Santiago Díaz de Leguizamo, 1522. Una de las preguntas contenidas en la pesquisa realizada al regreso de la Victoria a Sevilla, decía así: "[al margen: se dize que] De los juncos que tomaron en que yba un rey el qual dicen se rescató por çiertas coronas de oro de las que ponen sobre la cabeza y otras joyas de oro y oro en barras que dezian dio en mucha cantidad a un Juan Caraballo y a otros, porque le alargasen a él y los otros juncos que con él yban...". El piloto Albo declaró que oyó decir que le habían dado "un costalejo de algodón lleno de cosas que no sabe ni oyó desir de qué fuera lleno".

${ }^{91}$ AGI, Patronato, 34, R.11. Relación de personas que han fallecido en la Armada que el emperador Nuestro Señor envió al descubrimiento de la especiería de la cual era Capitán General Fernando de Magallanes. 1525. "En 15 de julio de 1521, estando las naos Trinidad e Vitoria surtas en el canal de Burney, cerca de la çibdad de Burney, se fueron e ausentaron de la dicha nao Vitoria: Juan Griego y Mateo Griego, marineros de la dicha nao Vitoria que se fueron con los moros a la çibdad de Burney".

92 Relación de personas que han fallecido en la Armada, 1525. AGI, Patronato, 34, R.11. "Un hijito de Juan Caravallo, piloto, que vino de la tierra de Brasil en una india, los cuales fueron a Burney por mandado del piloto Juan Caravallo que entonces era capitán mayor de la armada para coptar ciertas provisiones para el armada e después nos salimos de la barra desta ciudad de Burney porque venían muchas canoas de moros sobre nosotros e no pudimos esperar por miedo de las muchas calmas que en aquella tierra hay e la gente de las naos estaban flaca".

${ }^{93}$ Relación de Ginés de Mafra. En: La primera vuelta al mundo. Op. cit., p. 179. 
en cambio del capitán general al que libertó por oro" ${ }^{\text {94 }}$. Resulta cuando menos sorprendente que se hubiese permitido abandonar el barco a un niño de tan corta edad sin la compañía de su padre. La razón la desveló Juan Sebastián del Cano cuando un año más tarde declaraba en Sevilla ante el alcalde Leguizamo:

"E que vio que el dicho Caraballo enviaba rescates a su hijo de las mercaderías de S.M. con un primo suyo a la çibdad de Bruney..."

Quedaba en evidencia que cuando la flota hizo escala en Borneo, Carvallo, en lugar de bajar él mismo a tierra para entrevistarse con el rajá y comenzar a rescatar con los indios, decidió enviar a su hijo ciertas mercancías pertenecientes a la Corona o a los armadores de la flota, a modo de avanzadilla comercial, sin preocuparle lo más mínimo el peligro que el pequeño corría ${ }^{95}$. A Carvallo sólo le movía un afán: hacerse rico aun a costa de lo que fuera, aunque se tratara de la vida de su propio hijo.

La irregular actitud del jefe portugués y sus numerosas corruptelas -la última lo llevó a apropiarse en beneficio propio de tres mujeres que habían sido capturadas en Borneo- halló respuesta un buen día. Flotaba en el ambiente y en el ánimo de los compañeros un malestar imposible de disimular, que crecía a cada paso con tanta firmeza como el desprecio que sentían por Carvallo. "Por los desaguisados e deservicios que contra Su Magestad hasia..." se abrió un proceso contra el portugués y se le quitó la jefatura ${ }^{96}$. En su lugar fueron nombrados dos capitanes: Juan Sebastián del Cano en la Victoria, a quien además se confió la tesorería, y en la Trinidad, Gonzalo Gómez de Espinosa, el alguacil de la flota. Se eligió además a un contador en la persona de Martín Méndez, el escribano de la Victoria. A partir de entonces los tres compartían el mando de la debilitada flotilla de la Especiería. Ya por entonces el maestre vasco Juan Sebastián del Cano, hombre de pocas palabras, pero honrado y respetado por sus compañeros como ningún otro, se consagraba como líder indiscutible de aquella empresa.

Depuesto de su cargo y sin ninguna autoridad, Juan Carvallo consiguió llegar sano y salvo a las ansiadas islas Molucas. Cuando la flotilla almacenó en las bodegas todo el clavo de que fue capaz y los barcos emprendieron, cada uno por una ruta distinta, el tornaviaje a España, el piloto formaba parte de la tripulación de la Trinidad. No se tienen más noticias de él. Sólo el registro de su fallecimiento en la isla de Tidore un 14 de febrero de $1522^{97}$. Se desconocen las causas de la muerte.

\section{Juan Rodríguez Serrano, el viejo lobo de mar}

Juan Rodríguez Serrano o Juan Serrano, como también se le conocía, era el más entrado en años de los seis pilotos de la flota, tal y como lo demuestran los rasgos temblorosos de su firma y los comentarios de sus compañeros. Cuando se

\footnotetext{
${ }_{94}^{94}$ PIGAFETTA, Antonio. Primer Viaje en torno al globo... Op. cit, p.130.

${ }^{95}$ MAZÓN, Tomás. Elcano. Op. cit., p. 128.

${ }^{96}$ AGI, Patronato, 34, R.19. Información recibida por el alcalde de casa y corte, Santiago Díaz de Leguizamo 1522. Declaración de Juan Sebastián del Cano.

${ }_{97}$ AGI, Patronato, 34, R.20. Memoria de las personas que murieron en la nao Trinidad, siendo capitán Gonzalo Gómez de Espinosa, 1522.
} 
disponía a embarcar en la flota de la Especiería, al frente de la Santiago, Serrano era ya un viejo lobo de mar, curtido en tormentas y tempestades, y muy involucrado en el comercio atlántico y en las múltiples oportunidades que brindaban las tierras americanas. Aunque había nacido en Fregenal de la Sierra (Badajoz) ${ }^{98}$, tierra de fresnos y restos templarios, un buen dio encaminó sus pasos buscando el gran río y se avecindó en Sevilla en el bullicioso barrio de la Carretería, allí donde los afamados artesanos de la madera fabricaba pipas y toneles para las flotas que gozaban de tan merecida fama. Ya con muchos años a las espaldas, Juan se había casado en segundas nupcias con Juana Durango, una vecina sevillana que aportaría un hijo al matrimonio ${ }^{99}$.

Serrano entró a formar parte de la plantilla de pilotos reales el 8 de febrero de 1514 para cubrir las últimas vacantes, en vista de la falta de pilotos de que adolecía la armada de Pedrarias. De hecho, su nombramiento fue despachado a ultimísima hora y llegó a manos de los oficiales Matienzo y Recalde mediante un correo despachado "a toda furia" desde Madrid cuando ya la flota de Castilla del Oro ultimaba sus preparativos en Sanlúcar ${ }^{100}$. Dado que era un marino diestro y con mucha experiencia, se consideró que reunía más aptitudes que ninguno de sus colegas para ocupar el cargo de piloto mayor de la gran flota que se dirigía a las tierras americanas del Darién. No era la primera vez que Serrano surcaba las aguas caribeñas. Pedro Mártir de Anglería, bien informado de todo cuanto acontecía, escribió que Serrano había sido seleccionado para aquel cargo de piloto mayor porque "había navegado muchas veces por aquellas regiones"101, lo que demuestra que la experiencia en la navegación y en el conocimiento de las rutas "seguía siendo un valor mucho más cotizado que cualquier otro y que la teoría del arte náutico se reducía para la mayoría de los marinos de aquel entonces a la estima por rumbo y a la distancia calculada a ojo" ${ }^{102}$.

No se conoce en qué otros viajes participó Serrano tras su regreso del Darién. Las noticias más cercanas a 1519 lo muestran en comandita con varios maestres para negociar en Indias. Así en 1518 se sabe que el piloto se había asociado con Juan de Jerez y con Martín Núñez, este último maestre de la nao Santa María de la Antigua, para transportar mercancías y pasajeros a Santo Domingo y Puerto Rico y un año después, antes de zarpar con Magallanes, también mantenía vínculos

\footnotetext{
${ }^{98}$ Archivo de Torre do Tombo (Lisboa). Carta de Antonio de Brito al Rey de Portugal sobre algunos sucesos en la India y los del viaje de Magallanes. "Determinaron todos nombrar dos capitanes, a saber, Duarte Barbosa, portugués... y Juan Serrano, castellano". Fernández de Navarrete. FERNÁNDEZ DE NAVARRETE, Martín. Colección de los viajes... Op. cit., Doc. XXX, p. 595. Aunque durante algún tiempo se ha dudado del origen portugués de Serrano, no cabe duda de que era castellano y concretamente extremeño, como bien señalaba Peter BOYD BOWMAN en su Indice geobiográfico de más de 56 mil pobladores de la América hispánica, 1493-1519. México: FCE, 1985, p. 263. Lo corrobora la declaración del grumete Martín de Ayamonte de que era "castellano, natural de Frixinal". Publicada en: MAZÓN, Tomás. Elcano. Op. cit., p. 281.

${ }^{99}$ Consta que en 1514 todavía estaba casado con Juana Rodríguez del Castillo. MENA GARCIA, Carmen. Pilotos reales en la Armada de Castilla del Oro, 1514. En: Entre Puebla de los Ángeles y Sevilla. Estudios Americanistas en Homenaje al Dr. José Antonio Calderón Quijano. Sevilla: EE.HH.; CSIC; Universidad de Sevilla, 1997, pp. 41-60, p. 55.

100 MANZANO Y MANZANO, Juan y MANZANO FERNÁNDEZ DE HEREDIA, A. M. Los Pinzones y el Descubrimiento de América. Vol. II. Madrid: Ediciones de Cultura Hispánica, 1988, p. 552.

${ }_{101}$ ANGLERÍA, Pedro Mártir de. Décadas del Nuevo Mundo. Op. cit., p. 201.

${ }^{102}$ MENA GARCIA, Carmen. Sevilla y las flotas de Indias. Op. cit., p. 186.
} 
mercantiles con Gonzalo Rodríguez, vecino de Triana y maestre de la nao San Telmo ${ }^{103}$.

Cuando abandonó Sanlúcar al frente de la Santiago, Juan Serrano no viajaba solo. En esta ocasión se hacía acompañar de Francisco, el hijo de su esposa Juana Durango, tan sólo un niño, pues no debía de tener más de ocho años cuando su padrastro lo alistó como paje en su propia embarcación para que fuera aprendiendo el oficio de la marinería. También decidió embarcar con él a Juan, su esclavo negro, que entró a última hora para cubrir la vacante dejada por un grumete portugués. Curiosamente, a aquel que tan sólo cinco años atrás había sido elegido como piloto mayor de una gran flota compuesta por más de veinte embarcaciones y más de un millar de personas, se le relegaba ahora a pilotar la nave más pequeña, ocupando el puesto más irrelevante. ¿Acaso Serrano era ya demasiado mayor como para volver a confiar en él?

De la participación de Juan Serrano en la armada de las Molucas han quedado numerosas huellas. Se sabe que estando la flota en San Julián, y el invierno austral llegando a su fin, Magallanes envió a Serrano a que explorase la costa hacia adelante en busca del estrecho, pero pasado el rio de Santa Cruz se levantó un terrible temporal que dejó desarbolada a la Santiago. A pesar de la pericia del piloto, quien logró poner a salvo a casi toda la tripulación, aquel no pudo evitar que el barco encallase en unas peñas hasta hacerse pedazos. Con ello la flota ya sólo disponía de cuatro barcos.

En especial, se sabe también que Serrano no intervino en la conjura contra Magallanes ${ }^{104}$ y que éste recompensó su lealtad confiándole la capitanía de la Concepción, que había quedado descabezada, después de que el capitán Gaspar de Quesada fuera sentenciado por rebeldía y ejecutado ${ }^{105}$. Más adelante, tras la muerte de Magallanes en Mactán, las crónicas de la época cuentan que los supervivientes eligieron como jefes de la desbaratada flota al portugués Duarte Barbosa y a Juan Serrano, capitanes de la Trinidad y la Concepción, respectivamente, lo que indica que el piloto debía reunir notables condiciones para el liderazgo.

Por el contrario, queda por averiguar qué tipo de vínculo unía a Juan Serrano y al piloto Juan Carvallo, dado que Pigafetta alude insistentemente a ambos diciendo que eran "compadres"106. Si se descarta el significado más estricto del término (compadre: "padre con otro"), es decir el de la conexión existente entre el padrino y los padres de un niño por el sacramento del bautizo, lo más fácil es suponer que

\footnotetext{
${ }^{103}$ MENA GARCIA, Carmen. Pilotos reales...Op. cit., p. 55.

104 "El capitán Juan Rodríguez Serrano dixo en Santiago que la nao estaba por el Rey y por el capitán Hernando de Magallanes". HERRERA Y TORDESILLAS, Antonio de. Historia general de los hechos de los castellanos en las islas y tierra firme del mar océano, 1559-1625. Madrid: Imprenta real de Nicolás Rodríguez Franco, 1726. 4 vols. Tomo I, Década II, Lib.IX.

105 "y por haberle sido siempre leal, le dio la otra nao de que era capitán Gaspar de Quesada". PIGAFETTA, Antonio. Primer Viaje en torno al globo... Op. cit, p. 61.

106 PIGAFETTA, Antonio. Primer Viaje en torno al globo... Op. cit, p. 117. "Llama también así en Andalucía y otras partes la gente vulgar a sus amigos y suele ser modo de saludarse cuando se encuentran en los caminos y las posadas, unos con otros". RAE A 1729.
} 
fueran simplemente amigos (compadre: "compañeros") y que esa amistad bien pudo fraguarse a bordo de la Concepción o meses atrás.

La pista de Juan Serrano se pierde en las Filipinas, concretamente en la isla de Cebú tras un convite traicionero que prepararon los indios para acabar con las vidas de los huéspedes extranjeros. Duarte de Barbosa y Juan Serrano junto a veintisiete hombres entre los que se encontraba Francisco, el pequeño hijastro del piloto ${ }^{107}$, cayeron en esta terrible emboscada. Entre los últimos recuerdos que conservaba la tripulación cuando se alejaron a toda prisa de Cebú, Serrano aún estaba vivo. Desde la playa suplicaba entre lágrimas a sus compañeros que lo rescatasen: "este viejo decía el marinero Ginés de Mafra- con palabras y lágrimas, rogaba a los nuestros que se condoliesen de su vejez"108. Desde el barco le preguntaron a grandes voces qué había sucedido a sus compañeros a lo que el piloto respondió que los habían degollado a todos, excepto al esclavo de Magallanes que los había traicionado, uniéndose a los isleños. Serrano les suplicó que aceptasen rescatarlo por las mercancías que los indios exigían ${ }^{109}$, pero su compadre Juan Carvallo y algunos más que contemplaban la escena desde el barco rehusaron intentarlo siquiera. Eso dice Pigafetta, aunque otras versiones lo niegan ${ }^{110}$. El cronista italiano que no debía sentir mucha simpatía por Carvallo lo acusa directamente de haber abandonado a su "compadre" en estos trágicos momentos, sencillamente porque ansiaba hacerse con el mando de la flotilla. $Y$ finalmente, pone en boca de Juan Serrano la siguiente maldición:

"Juan Serrano siguió implorando la compasión de su compadre, diciendo que en cuanto nos hiciésemos a la vela lo asesinarían; y viendo, al fin, que sus lamentaciones eran inútiles, lanzó terribles imprecaciones, rogando a Dios que el día del juicio final hiciera dar cuenta de su alma a Juan Carvajo, su compadre"111.

Fue la última vez que lo vieron con vida. Su nombre figuraba en la lista de los caídos en aquel siniestro convite. Nadie podía testificar por vista de ojos la muerte de aquellos desgraciados, sólo se tenía la sospecha de que todos habían sido

\footnotetext{
107 Relación de las personas que han fallecido en la Armada, 1525. AGI, Patronato, 34. R.11. Las versiones sobre el número de hombres que asistieron al convite difieren según las crónicas. La relación de Mafra, por ejemplo, eleva la cifra a 53 personas. La lista oficial de los que asistieron al convite y fueron dados por desaparecidos registra un total de 27 bajas.

${ }^{108}$ Relación de Ginés de Mafra. En: La primera vuelta al mundo. Op. cit., p. 172.

109 Torre do Tombo (Lisboa). Carta de Antonio de Brito al Rey de Portugal sobre algunos sucesos en la India y los del viaje de Magallanes. FERNÁNDEZ DE NAVARRETE, Martín. Colección de los viajes... Op. cit., Doc. XXX, pp. 593-7. En la citada carta de Antonio de Brito al rey de Portugal éste informaba de que "los salvajes" había reclamado para liberar al piloto Serrano "dos bombardas y dos bares de cobre, y algunas bretañas o telas de lienzo de las que llevaban en las naves como mercaderías de trato y rescate".

110 Ginés de Mafra, por ejemplo, no señala a Carvallo. Recordaba aquel que los indios pidieron a cambio de la liberación de Serrano "un tiro de hierro" y asegura que se lo enviaron a tierra en un batel, pero pronto cayeron en la cuenta de que nunca conseguirían rescatar con vida al piloto. "Lo cual visto por los indios pidieron más, y así como concedían los nuestros en ello, añadían ellos a pedir más, hasta que conocida su intención los de las naos no quisieron más allí estar...y dijeron a Juan Serrano que se quedase con Dios y les perdonase". La primera vuelta al mundo. Op. cit., pp. 172-173.

${ }^{111}$ PIGAFETTA, Antonio. Primer Viaje en torno al globo... Op. cit, p. 117.
} 
asesinados por los indios ${ }^{112}$. Oficialmente, por tanto, ninguno podía ser dado por muerto, y mucho menos Juan Serrano, lo cual trajo a los familiares de aquellos desgraciados numerosos inconvenientes hasta conseguir que la Corona les liquidara sus sueldos.

Cuando tuvo noticias de la desaparición de Juan Serrano, su esposa, Juana Durango, lo intentó todo para recuperar a su marido ${ }^{113}$. De alguna manera logró entrar en contacto en 1527 con Fernando Suárez, el tesorero general del rey de Portugal, y ante un escribano le ofreció 150 ducados de oro por el rescate de su esposo, que estaba según ella misma explicó, "cautivo de los moros en la India de Portugal" ${ }^{14}$. Juana aún no había perdido la esperanza de que el piloto siguiera con vida. Y cuatro años más tarde nombraba a Diego Pizarro y a Fernando Dávila, respectivamente, sus procuradores ante el Consejo de Indias para que solicitasen el abono del salario debido a su esposo como capitán y piloto de Sus Majestades. Todavía seguía insistiendo en que su marido estaba "cautivo de los moros", y confiaba en verlo regresar ${ }^{115}$.

\section{Bibliografía}

ANGLERÍA, Pedro Mártir de. Décadas del Nuevo Mundo. Edición de Ramón Alba. Madrid: Ediciones Polifemo, 1989.

BARROS, Joao de. Décadas de Asia (1552-1615). Lisboa: Divisao de Publicacoes e Biblioteca Agencia Geral das colonias, 1946. 4 vols.

BOYD BOWMAN, Peter. Indice geobiográfico de más de 56 mil pobladores de la América hispánica, 1493-1519. México: FCE, 1985.

CAVIGLIA, Sergio Esteban. Malvinas: Soberanía, Memoria y Justicia: 10 de Junio de 1829 [en línea]. Ministerio de Educación de la Provincia de Chubut, 2012, pp. 52 53.

\footnotetext{
${ }^{112}$ AGI, Patronato, 34. R.11. Relación de las personas que han fallecido en la Armada, 1525. " 1 de mayo de 1521 mataron a trayçión en Çebu las personas siguientes, las quales estaban todas en tierra e creemos ser todos muertos".

${ }^{113}$ APS, 25. Oficio V. Libro I. Escribanía de Francisco Castellanos. Fecha: 28, marzo, 1525. Juana Durango, mujer de Juan Rodríguez serrano, piloto de Sus Majestades, vecina de Sevilla en la collación de la Carretería, otorga poder a Alonso de Ara, criado del Almirante de las Indias, para que en su nombre comparezca ante Sus Majestades o ante los señores del Consejo Real de las Indias y les reclamen los maravedís que le deben.

114 APS, 3.268. Oficio V. Libro II. Escribanía de Francisco Castellanos. Fecha: 12, marzo, 1527. Presentó como fiadores a Gonzalo Rodríguez, vecino de Triana y a Beatriz de Atienza, viuda de Pedro Durango, vecina de Sevilla.

${ }^{115}$ APS, 39, Oficio I. Libro I. Escribanía de Alonso de la Barrera. Fecha: 13 de marzo de 1531; APS, 52. Oficio I. Libro I. Escribanía Alonso de la Barrera. Fecha: 30 de mayo de 1531. Ese mismo año, el 9 de junio Juana Durango nombraba también procurador a Pedro Álvarez, mercader, vecino de Sevilla. Oficio III, Lib. I. Escribanía Antón Ruiz de Porras. Fecha: 9, junio, 1531. Catálogo de los Fondos Americanos del Archivo de Protocolos de Sevilla. Tomo VI. Sevilla: Instituto Hispano Cubano, 1986. AGI, Contratación, 4675B, L.5. En 24 de junio de 1533, la Corona hizo merced a Juana Durango, vecina de Moguer, de 20 ducados "de limosna". APS, 1073. Oficio I. Escribanía de Gonzalo de Toledo. Fecha: 25 de septiembre de 1538. En 1538 Juana Durango seguía solicitando ante el Consejo de Indias el sueldo anual de su esposo.
} 
$<$ https://commons.wikimedia.org/wiki/File:Primer mapa de las Islas Malvinas ( 1520) por Andr\%C3\%A9s de San Mart\%C3\%ADn.jpg>.

CEREZO, Ricardo. Conjetura y realidad geográfica en la primera circunnavegación a la tierra. En: Actas del Congreso de Historia del Descubrimiento. Tomo II. Madrid: Real Academia de la Historia; Confederación española de Cajas de Ahorros, 1992, pp. 137192.

COMELLAS, José Luis. La primera vuelta al mundo. Madrid: Rialp, 2012.

CHAVES, Alonso de. Espejo de Navegantes, ca. 1537. Edición y estudio preliminar de Paulino Castañeda, Mariano Cuesta y Pilar Hernández. Madrid: Museo Naval, 1983.

FERNÁNDEZ DE NAVARRETE, Martín. Colección de los viajes y descubrimientos que hicieron por mar los españoles desde fines del siglo XV. BAE, tomo LXXVI, vol. II. Edición y estudio preliminar de Carlos seco Serrano. Madrid: Atlas, 1964.

GIL FERNÁNDEZ, Juan. Marinos y mercaderes en Indias. Anuario de Estudios Americanos. 1985, n. 42, pp. 297- 499.

GIL FERNÁNDEZ, Juan. El libro de Marco Polo anotado por Cristóbal Colón. Madrid: Alianza, 1987.

GIMÉNEZ FERNÁNDEZ, Manuel. Bartolomé de las Casas. Tomo II: Política inicial de Carlos I en Indias. Sevilla: Escuela de Estudios Hispanoamericanos, 1960.

GUEDES, Max Justo. A Armada de Fernão de Magalhães e o Brasil. En: A viagem de Fernão de Magalhães e a questão das Molucas. Actas do II Colóquio luso espanhol de Historia Ultramarina. Lisboa: Junta de Investigaciones Científicas de Ultramar, 1975, pp. 363-377.

HERRERA Y TORDESILLAS, Antonio de. Historia general de los hechos de los castellanos en las islas y tierra firme del mar océano, 1559-1625. Madrid: Imprenta real de Nicolás Rodríguez Franco, 1726. 4 vols.

LADERO QUESADA, Miguel Ángel. Las Indias de Castilla en sus primeros años. Cuentas de la Casa de la Contratación (1503-1521). Madrid: Dykinson, S.L., 2008.

LAGUARDA TRIAS, Rolando. Las longitudes geográficas. En: A viagem de Fernão de Magalhães e a questão das Molucas. Actas do II Colóquio luso espanhol de Historia Ultramarina. Lisboa: Junta de Investigaciones Científicas de Ultramar, 1975, pp. 135178.

LAGUARDA TRIAS, Rolando. El cosmógrafo sevillano Andrés de San Martín, inventor de las cartas esféricas. Montevideo: Imprenta Militar, 1991.

LÓPEZ DE GÓMARA, Francisco. Historia General de las Indias. Caracas: Biblioteca Ayacucho, 1978.

MANZANO Y MANZANO, Juan y MANZANO FERNÁNDEZ DE HEREDIA, A. M. Los Pinzones y el Descubrimiento de América. Madrid: Ediciones de Cultura Hispánica, 1988. 3 vols. 
MAZÓN, Tomás. Elcano. Viaje a la Historia. Madrid: Ediciones Encuentros, 2020.

MEDINA, José Toribio. El portugués Esteban Gómez al servicio de España: Estudio histórico. Santiago de Chile: Imprenta Elzeviriana, 1908.

MELÓN Y RUIZ DE GORDEJUELA, Amando. Magallanes-Elcano o la primera vuelta al mundo. Zaragoza: Ed. Luz, 1940.

MENA GARCIA, Carmen. Pilotos reales en la Armada de Castilla del Oro, 1514. En: Entre Puebla de los Ángeles y Sevilla. Estudios Americanistas en Homenaje al Dr. José Antonio Calderón Quijano. Sevilla: EE.HH.; CSIC; Universidad de Sevilla, 1997, pp. 41-60.

MENA GARCIA, Carmen. Sevilla y las flotas de Indias. La gran armada de Castilla del Oro, 1513-1514. Sevilla: Fundación El Monte; Universidad de Sevilla, 1998 (1를 ed.) y 1999 ( $2^{\underline{a}}$ ed.).

MENA GARCIA, Carmen. Conocer y dominar los astros. El piloto Andrés de San Martín y la expedición de Magallanes/Del Cano. Temas Americanistas. Jun. 2020, n. 44, pp. 197231.

ORTEGA, OFM. P. Ángel. La Rábida. Historia documental y crítica. Sevilla: Imprenta de San Antonio, 1925. 4 vols.

PÉREZ MALLAINA, Pablo E. Los hombres del Océano. Vida cotidiana de los tripulantes de las flotas de Indias, siglo XVI. Sevilla: Diputación Provincial de Sevilla, 1992.

PÉREZ DE TUDELA BUESO, Juan. La Especiería de Castilla. En: A viagem de Fernão de Magalhães e a questão das Molucas. Actas do II Colóquio luso espanhol de Historia Ultramarina. Lisboa: Junta de Investigaciones Científicas de Ultramar, 1975, pp. 627688.

PIGAFETTA, Antonio. Primer Viaje en torno al globo. Madrid: Espasa Calpe, 1999.

PORTUONDO, María M. Ciencia secreta. La cosmografía española del Nuevo Mundo. Madrid: Iberoamericana-Vervuert, 2013.

ROMERO TALLAFIGO, Manuel. El testamento de Juan Sebastián Elcano (1526). Palabras para un autorretrato. Sevilla: Editorial Universitaria de Sevilla, 2021.

SCHÄFER, Ernesto. El Consejo Real y Supremo de las Indias. Su historia, organización y labor administrativa hasta la terminación de la Casa de Austria. Sevilla: Imprenta M. Carmona, 1935. 2 vol.

VIGNERAS, Louis André. El viaje de Esteban Gómez a Norteamérica. Revista de Indias. 1957, n. 68, pp. 189-207. 